\title{
Discovery of Pyridazinone and Pyrazolo[1,5-a]pyridine Inhibitors of C-terminal Src Kinase
}

Daniel P. O’Malley*, Vijay Ahuja, Brian Fink, Carolyn Cao, Cindy Wang, Jesse Swanson, Susan Wee, Ashvinikumar V. Gavai, John Tokarski, David Critton, Anthony A. Paiva, Benjamin M. Johnson, Nicolas Szapiel, Dianlin Xie

Table of Contents

Production and purification of protein for crystallography

Procedure for cyrstallization of compound $\mathbf{1 1}$ with Lck 2

Procedure for HTRF assays $\quad 2$

Procedure for Caliper assays $\quad 3$

Procedure for protein binding and metabolic stability assays 3

Procedure for ZAP70 assay $\quad 4$

Procedure for PK/PD experiments $\quad 4$

Procedure for $\mathrm{CHO} /$ Tcell assay $\quad 4$

Replicate numbers for Table 1 and Table 2

Synthetic procedures $\quad$ 5-24

Copy of spectra for compound $4 \quad 25-26$

Copy of spectra for compound $13 \quad 27-29$

Kinome data for compounds 4, 6, 13 and $14 \quad 30$ 
Production of LCK protein for crystallography:

Large scale protein production was carried out in a $50 \mathrm{~L}$ cell bag using WAVE-Bioreactor System 20/50 (GE Healthcare Bioscience). A 24L of $2 \times 10^{6}$ cells $/ \mathrm{ml} \mathrm{Sf9}$ cells in ESF921 insect medium (Expression System) was infected with His-TVMV-hLck(225-509)-pFB P2 virus stock (5ml/L) at $27^{\circ} \mathrm{C}$ for 66 hours. The infected cells were harvested by centrifugation at $2000 \mathrm{rpm}$ for $20 \mathrm{~min}$ at $4{ }^{\circ} \mathrm{C}$ in a SORVALL ${ }^{\circledR} \mathrm{RC} 12 \mathrm{BP}$ centrifuge. The cell pellets were washed once with cold PBS buffer and was stored at $-70 \stackrel{\circ}{ }$ before protein was purified.

Purification of LCK protein for crystallography:

All steps performed at $4^{\circ} \mathrm{C}$ unless otherwise noted. SF9 Baculovirus transfected cell paste was resuspended in $50 \mathrm{mM}$ Tris- $\mathrm{HCl}$ pH 8.0, $300 \mathrm{mM} \mathrm{NaCl}, 20 \mathrm{mM}$ Imidazole, $5 \%$ (v/v) Glycerol, $1 \mathrm{mM}$ DTT with $25 \mathrm{U} / \mathrm{ml}$ Benzonase (Sigma-Aldrich) and complete protease inhibitors (Roche). Cells lysed by nitrogen cavitation and clarified by centrifugation at $17,080 \times \mathrm{g}$ for 75 minutes. Protein prepared on AKTA FPLC: initial capture by nickel affinity, followed by TVMV protease digest and dialysis, nickel affinity in flowthrough mode to remove residual reaction components and final size exclusion chromatography on Superdex 200 26/60 (GE). Purified hLCK kinase pool activated by incubation with ATP and $\mathrm{MgCl}_{2}$ at room temperature for 6 minutes, enzymatic reaction quenched with excess EDTA. As a final polishing step to separate mono-phosphorylated and bis-phosphorylated hLCK, the activated kinase pool was loaded on a Mono-Q 10/100 GL (GE), a shallow $\mathrm{NaCl}$ elution gradient allowed separation of two species: obtained 5 $\mathrm{mg}$ of mono-phosphorylated $\mathrm{hLCK}$ and $1 \mathrm{mg}$ of bis-phosphorylated $\mathrm{hLCK}$, protein stored at $-80^{\circ} \mathrm{C}$. Purified and activated mono-phosphorylated hLCK was used for crystallography studies.

\section{Crystallization}

Apo LCK was crystallized as follows: $1 \mu \mathrm{L} \mathrm{LCK}$ at $4 \mathrm{mg} / \mathrm{mL}$ was combined with an equal volume of precipitant (1.5 M ammonium sulfate, $120 \mathrm{mM}$ lithium chloride, $10 \mathrm{mM}$ nickel(II) chloride, $100 \mathrm{mM}$ CAPS $\mathrm{pH}$ 10.5) on a cover slide over a reservoir containing $500 \mu \mathrm{L}$ precipitant in a hanging drop vapor diffusion crystallization tray incubated at $18^{\circ} \mathrm{C}$. Initial crystals developed within one day and grew to full size within one week. Full-size crystals were transferred to a $1 \mu \mathrm{L}$ drop of precipitant solution supplemented with $1 \mathrm{mM}$ of 11 and soaked for 18 hours at $18^{\circ} \mathrm{C}$. Soaked crystals were cryoprotected by brief washing through a $1 \mu \mathrm{L}$ drop of precipitant supplemented with $1 \mathrm{mM}$ of 11 and $10 \%(\mathrm{v} / \mathrm{v}$ ) each of glycerol and PEG 400, after which they were flash frozen in liquid nitrogen prior to X-ray data collection.

Data Processing and Structure Determination

Crystallographic diffraction data for the LCK+11 complex was collected at a wavelength of $1.0 \AA$ and temperature of $100 \mathrm{~K}$ at Advanced Photon Source IMCA-CAT beamline 17ID, with data reduction carried out using autoPROC (Vonrhein et al. (2011) Acta Cryst. D v67: pp293-302). The crystal structure of the LCK+11 complex was determined by molecular replacement using the Phaser crystallographic software (McCoy et al. (2007) J. Appl. Cryst. v40: pp658-674) and the protein coordinates from the LCK+staurosporine complex (RCSB PDBID 1QPJ) as an input model; model building was completed using Coot (Emsley et al. (2010) Acta Cryst. D v66: pp486-501) and refinement carried out using autoBUSTER (Global Phasing Ltd.).

Accession Numbers

Coordinates and structure factors for the LCK+11 complex have been deposited in the Rutgers Center for Structural Biology (RCSB) Protein Data Bank (PDB) under accession number 6DPJ.

Procedure for HTRF assays:

A time resolved FRET-based competition binding assay was used to assess test article binding to the kinase of interest. His-tagged or GST-tagged kinase at a concentration of $1 \mathrm{nM}$ was incubated with 0.2 
nM Tb-labeled detection antibody (anti-His or anti-GST), test compound, and fluorescein-labeled ATP competitive probe at a concentration corresponding to the probe's equilibrium dissociation constant for one hour. Fluorescence at $495 \mathrm{~nm}$ and $520 \mathrm{~nm}$ was measured using an EnVision microplate reader to quantify FRET between Tb-labeled detection antibody and fluorescein-labeled probe. Background subtracted FRET ratios were normalized to the maximum signal obtained in the absence of test compound. These values were converted to a percent inhibition. Percent inhibition was determined for test compounds at 11 concentrations. The $\mathrm{IC}_{50}$, defined as the concentration of competing test compound needed to reduce specific binding of the probe by $50 \%$, was calculated using the 4 parameter logistic equation to fit the data.

Procedure for Caliper assays:

$10 \mathrm{mM} \mathrm{MgCl} 2,0.015 \%$ Brij-15 and 2 mM DTT containing 1.5 uM fluorescently-labeled peptide substrate, ATP at $\mathrm{Km}$, and various concentrations of compound. Reaction incubation times and enzyme concentrations were optimized to obtain a maximum peptide substrate conversion of $10-30 \%$ and reactions were quenched with $1 \mathrm{mM}$ EDTA solution. Reaction mixtures were analyzed by capilary electrophoresis on a Caliper LabChip EZ Reader to resolve phosphorylated and unphosphorylated peptide species and determine peptide substrate conversion. Percent inhibition was calculated from the substrate conversion generated by no enzyme control reactions for $100 \%$ inhibition and vehicle-only reactions for $0 \%$ inhibition. Compounds were dissolved in DMSO and evaluated at 11 concentrations to determine $\mathrm{IC}_{50}$.

Procedure for protein binding assay:

Compounds were tested in a panel of multi-species serum protein binding assays to determine the extent to which this compound binds to serum proteins in various species. Compounds were assayed in triplicate by combining with serum from an individual species of interest (human or mouse serum) to achieve final concentration of $10 \mu \mathrm{M}$. Dialysis was performed for 5 hours at $37^{\circ} \mathrm{C}$, in a $10 \% \mathrm{CO}_{2}$ atmosphere against sodium phosphate buffer using the two-chamber Rapid Equilibrium Dialysis (RED) Assay Plates from Thermo Fisher (Waltham, Massachusetts). Assay samples from buffer and serum chambers were collected at time zero (TO[Serum] and TO[Buffer]) and at 5 hours post-incubation (postequilibration, T5h[Serum] and T5h[Buffer]). Samples were analyzed by liquid chromatography followed by tandem mass spectrometry (LC-MS/MS) to assess the fraction of compound (percentage) free to diffuse and equilibrate between the buffer and serum chambers in the dialysis device. Prior to LCMS/MS analysis, assay samples were diluted with either buffer or serum to result in the same final serum concentration in each sample. Subsequently, these samples were extracted by protein precipitation in acetonitrile containing analytical internal standards. Samples were analyzed by LC$\mathrm{MS} / \mathrm{MS}$ and relative amounts of test compound were determined by calculating the peak area ratio of test compound to internal standard in each sample. Results were expressed as the percent of test compound free (unbound), percent bound, and percent recovered after incubation.

Procedure for metabolic stability assays:

Compounds were tested in a panel of Metabolic Stability Assays to determine its in vitro half-life (THALF) and the rate of CYP-mediated metabolism in incubations with NADPH-fortified human and mouse liver microsomes. Test compound $(0.5 \mu \mathrm{M})$ was incubated with NADPH-fortified liver microsomes (1 $\mathrm{mg} / \mathrm{mL}$ ) at $37^{\circ} \mathrm{C}$. Metabolic reactions were terminated after $0,5,10,15,30$, and 45 minutes by transferring an aliquot of the reaction mixtures into a quench solution to denature microsomal enzymes. The relative amount of the test compound remaining in the reaction mixtures at each time point was quantified using LC-MS/MS analysis. The results for each time point were normalized to the relative amount of test compound in the 0 -minute sample and expressed as percent remaining. The half-life ( $\mathrm{T}$ HALF), rate of metabolism, hepatic intrinsic clearance (CLh,int), and hepatic blood clearance (CLh,b) for 
test compound were calculated based on elimination rate constant (kel), which was determined using linear regression model (natural logarithm of \% Remaining versus time).

Procedure for ZAP 70 assay:

Jurkat cells were pre-treated with CSK compounds for 30 minutes then stimulated with anti-CD3/CD28 at $1 \mathrm{ug} / \mathrm{ml}$ for 10 minutes. Cells were then harvested and lysed with RIPA buffer. Levels of phosphorylated Zap70 was detected with pZAP70 antibody (Tyr493) from Cell Signaling (\#2704) and normalized to total ZAP70 antibody from Cell Signaling (\#2705).

Procedure for PK/PD assay:

$\mathrm{C} 57 \mathrm{bl} / 6$ mice were dosed PO with the indicated CSK compound. At the indicated time points spleens were harvested and homogenized in RIPA buffer using Tissuelyser (Qiagen). Levels of phosphorylated LCK tyrosine 505 protein was detected with Cell Signaling antibody (\#2751) and normalized to total LCK (\#2752)

Procedure for CHO-OKT3 assay:

$\mathrm{CHO}$ cells were stably engineered to overexpress the anti-human CD3 IgG monoclonal antibody clone OKT3. Primary human T cells were pre-treated with DMSO control or CSK compound in a $96 \mathrm{U}$-bottom plate for 15 minutes followed by a complete media exchange. CHO-OKT3 cells were then added at a 1:8 ratio of CHO-OKT3 to primary human T cells. Supernatant was collected at 48 hours post-treatment to measure IL2 levels by AlphaLISA (PerkinElmer) and 72 hours to measure proliferation by MTS (Promega).

Replicate numbers for Table 1 and Table 2:

Table 1. Characterization of Csk inhibitors 1-6., ${ }^{\text {b }}$

\begin{tabular}{|l|l|l|l|l|l|l|l|}
\hline Cpd & $\begin{array}{l}\text { Csk IC }_{50} \\
(\mathrm{nM})\end{array}$ & $\mathrm{n}$ & $\begin{array}{l}\text { Lck IC }_{50} \\
(\mathrm{nM})\end{array}$ & $\mathrm{n}$ & $\begin{array}{l}\text { ZAP-70 EC } \\
\left(\mathrm{Y}_{\max }\right)\end{array}$ & $\mathrm{n}$ & $\begin{array}{l}\text { HLM/MsLM } \\
\% \text { Rem. }\end{array}$ \\
\hline 1 & 5600 & 1 & $>50000$ & 1 & $7900(73 \%)$ & 1 & $2 / 33$ \\
\hline 2 & 79 & 1 & 24000 & 1 & $5700(180 \%)$ & 2 & $65 / 15$ \\
\hline 3 & 80 & 1 & 31000 & 1 & $4050(350 \%)$ & 2 & $68 / 9$ \\
\hline 4 & 70 & 3 & 43000 & 3 & $2000(350 \%)$ & 6 & $53 / 78$ \\
\hline 5 & 430 & 1 & 34000 & 1 & $2700(280 \%)$ & 1 & $72 / 1$ \\
\hline 6 & 8 & 3 & 26000 & 3 & $420(270) \%$ & 2 & $61 / 59$ \\
\hline
\end{tabular}

${ }^{b}$ HLM: Human liver microsomes. MsLM: Mouse liver microsomes.

Table 2. Characterization of Csk inhibitors 7-14. ${ }^{b}$

\begin{tabular}{|c|c|c|c|c|c|c|c|c|c|}
\hline \multirow[t]{2}{*}{ Cpd } & \multicolumn{4}{|c|}{$\operatorname{Csk} \mathrm{IC}_{50}(\mathrm{nM})$} & \multirow{2}{*}{$\begin{array}{l}\text { Lck IC }_{50} \\
\text { (nM) }\end{array}$} & \multirow[t]{2}{*}{$\mathrm{n}$} & \multirow{2}{*}{$\begin{array}{l}\text { ZAP-70 EC } \\
(n M)\left(Y_{\text {max }}\right)\end{array}$} & \multirow[t]{2}{*}{$n$} & \multirow{2}{*}{$\begin{array}{l}\text { HLM/ } \\
\text { MsLM } \\
\text { \%Rem }\end{array}$} \\
\hline & HTRF & $n$ & Caliper & $n$ & & & & & \\
\hline 7 & 5 & 1 & 4 & 1 & 300 & 1 & $49(250 \%)$ & 1 & $84 / 24$ \\
\hline 8 & $<3$ & 2 & 4 & 2 & 120 & 2 & $42(190 \%)$ & 4 & $72 / 10$ \\
\hline 9 & 26 & 2 & 21 & 2 & 3100 & 2 & $1400(240 \%)$ & 1 & $71 / 21$ \\
\hline 10 & $<3$ & 2 & 2 & 2 & 26 & 2 & $28(220 \%)$ & 2 & $80 / 2$ \\
\hline 11 & 42 & 1 & 13 & 1 & 42 & 1 & $>20000$ & 1 & NT/59 \\
\hline 12 & $<3$ & 1 & 4 & 1 & 230 & 1 & $88(370 \%)$ & 1 & $85 / 9$ \\
\hline 13 & $<3$ & 3 & 4 & 4 & 260 & 3 & $41(360 \%)$ & 4 & $91 / 100$ \\
\hline 14 & 4 & 2 & 6 & 2 & 110 & 2 & $56(210 \%)$ & 4 & $85 / 99$ \\
\hline
\end{tabular}

${ }^{b} \mathrm{NT}$ : not tested. 
Procedure for metabolic soft spot analysis:

These experiments were performed as described in Paiva, A. A.; Klakouski, C.; Li, S.; Johnson, B. M.; Shu, Y.-Z.; Josephs, J.; Zvyaga, T; Zamora, I.; Shou, W. Z. Development, optimization, and implementation of a centralized metabolic soft spot assay. Bioanal. 2017, 9, 541-552.

Experimentals:

General Synthetic Methods:

Reactions were carried out under an inert atmosphere and at room temperature unless otherwise noted. Anhydrous solvents were purchased and used without further purification or drying.

LCMS methods:

Method A: Column: Acquity BEH C18, $2.1 \mathrm{~mm}$ x $50 \mathrm{~mm}, 1.7 \mu \mathrm{m}$ particles; Mobile Phase A: water with with $0.05 \%$ TFA; Mobile Phase B: acetonitrile 0.05\% TFA; Gradient: $2 \%$ B to $98 \%$ B over 1 min ,then a 0.5 min hold at $98 \%$ B; Flow: $0.8 \mathrm{~mL} / \mathrm{min}$;

Method B: Column: Waters Acquity UPLC BEH C18, 2.1 x $50 \mathrm{~mm}, 1.7-\mu \mathrm{m}$ particles; Mobile Phase A: 5:95 acetonitrile:water with $10 \mathrm{mM}$ ammonium acetate; Mobile Phase B: 95:5 acetonitrile:water with $10 \mathrm{mM}$ ammonium acetate; Temperature: $50^{\circ} \mathrm{C}$; Gradient: $0-100 \%$ B over 3 minutes, then a 0.75 -minute hold at 100\% B; Flow: $1.11 \mathrm{~mL} / \mathrm{min}$; Detection: UV at $220 \mathrm{~nm}$.

Method C: Column: Waters Acquity UPLC BEH C18, 2.1 x 50 mm, 1.7- $\mu \mathrm{m}$ particles; Mobile Phase A: 5:95 acetonitrile:water with 0.1\% trifluoroacetic acid; Mobile Phase B: 95:5 acetonitrile:water with 0.1\% trifluoroacetic acid; Temperature: $50{ }^{\circ} \mathrm{C}$; Gradient: 0-100\% B over 3 minutes, then a 0.75 -minute hold at $100 \%$ B; Flow: $1.0 \mathrm{~mL} / \mathrm{min}$; Detection: UV at $220 \mathrm{~nm}$.

HPLC methods:

Method A: Column: Xbridge phenyl, 4.6 x $150 \mathrm{~mm}$, 3.5- $\mu \mathrm{m}$ particles; Mobile Phase A: 5:95

methanol:water with $10 \mathrm{mM} \mathrm{NH}_{4} \mathrm{HCO}_{3}$; Mobile Phase B: 95:5 methanol:water with $10 \mathrm{mM} \mathrm{NH}_{4} \mathrm{HCO}_{3}$;; Gradient: $10-100 \%$ B over 25 minutes, then a 5-minute hold at 100\% B; Flow: $2.0 \mathrm{~mL} / \mathrm{min}$; Detection: UV at $254 \mathrm{~nm}$.

Method B: Column: Sunfire C18 3.6 x 150 mm, 3.5- $\mu$ m particles; Mobile Phase A: 5:95 methanol:water with 0.05\% TFA; Mobile Phase B: 95:5 methanol:water with 0.05\% TF;; Gradient: 10-100\% B over 12 minutes, then a 3-minute hold at 100\% B; Flow: $1.0 \mathrm{~mL} / \mathrm{min}$; Detection: UV at $220 \mathrm{~nm}$.

Preparation of compound 1: 

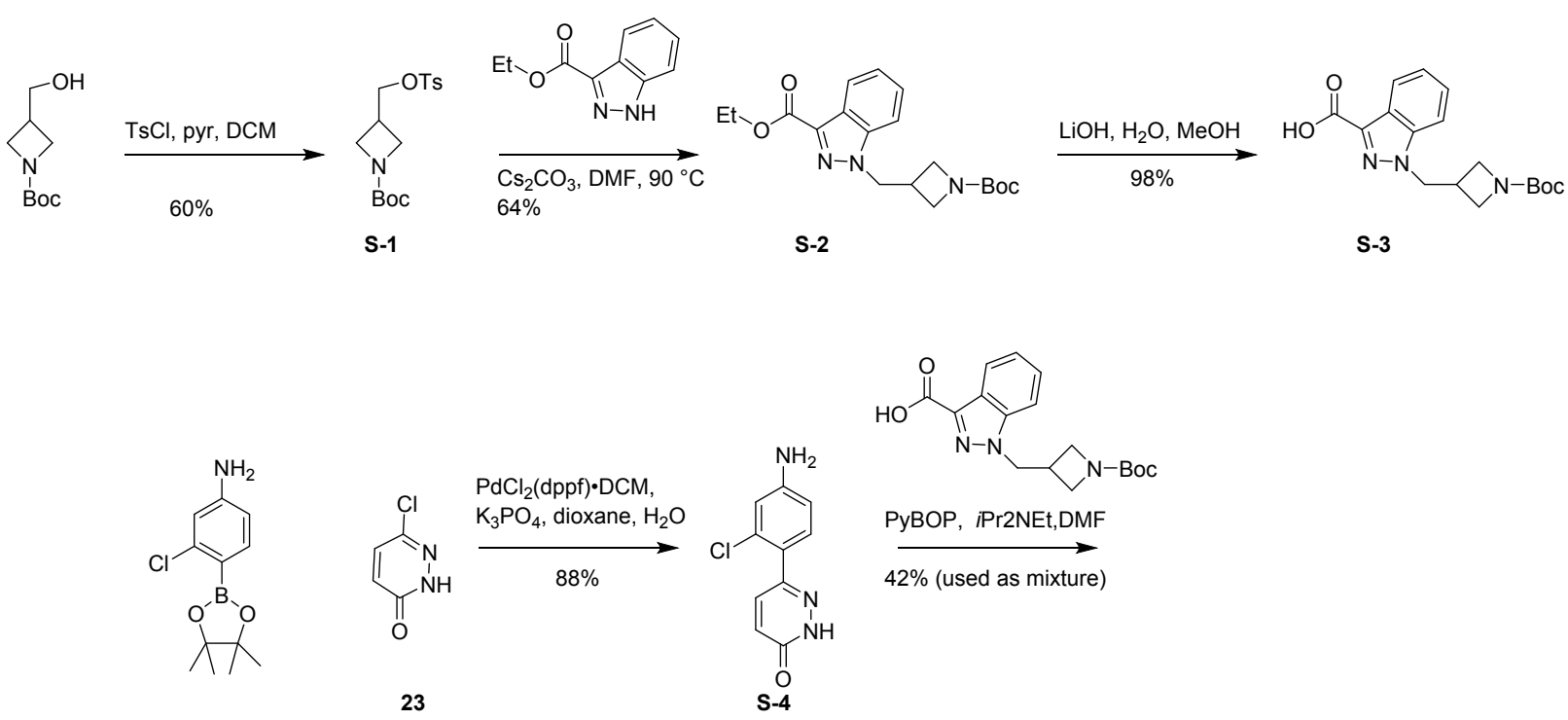

$42 \%$ (used as mixture)

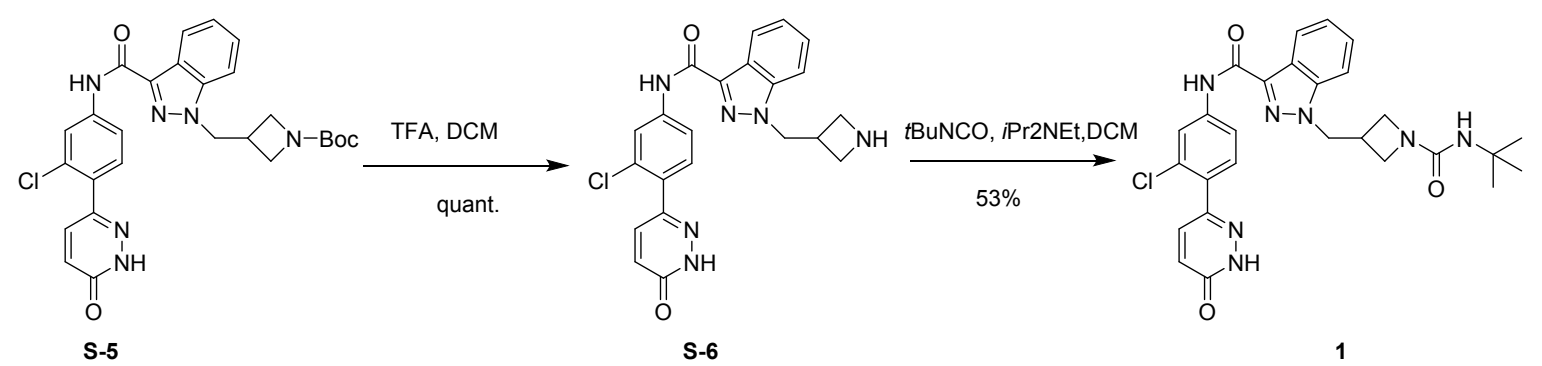

Synthesis of tert-butyl 3-((tosyloxy)methyl)azetidine-1-carboxylate (S-1):

Tert-butyl 3-(hydroxymethyl)azetidine-1-carboxylate $(1 \mathrm{~g}, 5.34 \mathrm{mmol})$ and pyridine $(0.5 \mathrm{~mL})$ was dissolved in DCM $10 \mathrm{~mL}$ and cooled to $0^{\circ} \mathrm{C}$. Tosyl Chloride $(1.069 \mathrm{~g}, 5.61 \mathrm{mmol})$ was added and the reaction was stirred in the ice bath for 30 minutes and stirred at $\mathrm{rt}$ for an additional $12 \mathrm{~h}$. Then the mixture was diluted with $20 \mathrm{~mL}$ of $\mathrm{NaHCO}_{3}(\mathrm{aq})$ and $40 \mathrm{~mL}$ of DCM. The organic layer was washed with brine and dried over $\mathrm{Na}_{2} \mathrm{SO}_{4}$, then concentrated. The residue was was loaded onto $24 \mathrm{~g}$ ISCO silica column, eluted with $0 \rightarrow 60 \%$ EtOAc in Hexane to afford tert-butyl 3-((tosyloxy)methyl)azetidine-1carboxylate (S-1) $\left(1.1 \mathrm{~g}, 3.22 \mathrm{mmol}, 60.3 \%\right.$ yield). ${ }^{1} \mathrm{H}$ NMR (400 MHz, CHLOROFORM-d) $\delta 7.78-7.74$ (m, $2 \mathrm{H}), 7.34(\mathrm{dd}, \mathrm{J}=8.6,0.6 \mathrm{~Hz}, 2 \mathrm{H}), 4.11(\mathrm{~d}, \mathrm{~J}=6.8 \mathrm{~Hz}, 2 \mathrm{H}), 3.95-3.89(\mathrm{~m}, 3 \mathrm{H}), 3.66(\mathrm{dd}, \mathrm{J}=8.7,5.2 \mathrm{~Hz}, 1 \mathrm{H})$, $3.56(\mathrm{br} \mathrm{dd}, \mathrm{J}=8.8,5.3 \mathrm{~Hz}, 2 \mathrm{H}), 2.80$ (tddd, J=10.1, 5.1, 3.4, $1.6 \mathrm{~Hz}, 1 \mathrm{H}), 2.43(\mathrm{~s}, 3 \mathrm{H}), 1.39(\mathrm{~s}, 9 \mathrm{H})$

Preparation of (ethyl 1-((1-(tert-butoxycarbonyl)azetidin-3-yl)methyl)-1H-indazole-3-carboxylate (S-2): A mixture of ethyl $1 \mathrm{H}$-indazole-3-carboxylate $(300 \mathrm{mg}, 1.577 \mathrm{mmol})$, tert-butyl 3-

((tosyloxy)methyl)azetidine-1-carboxylate (S-1) $(754 \mathrm{mg}, 2.208 \mathrm{mmol}$ ) and cesium carbonate (1028 mg, $3.15 \mathrm{mmol})$ in DMF $(7.89 \mathrm{~mL})$ was stirred at $90^{\circ} \mathrm{C}$ for $12 \mathrm{~h}$. The reaction was iluted with water, extracted with EtOAc, washed organic layer with, brine, concentrated and the residue was loaded onto a 40g ISCO silica column, eluted with EtOAc/Hex (0-60\%). The undesired regioisomer eluted first and the desired regioisomer eluted second. Fractions containing the desired product were concentrated to give ethyl 1-((1-(tert-butoxycarbonyl)azetidin-3-yl)methyl)-1H-indazole-3-carboxylate (S-2) (362 mg, 1.007 mmol, $63.9 \%$ yield). ${ }^{1} \mathrm{H}$ NMR (400 MHz, CHLOROFORM-d) $\delta 8.25-8.19(\mathrm{~m}, 1 \mathrm{H}), 7.53-7.42(\mathrm{~m}, 2 \mathrm{H}), 7.36$ - $7.27(\mathrm{~m}, 1 \mathrm{H}), 4.67(\mathrm{~d}, \mathrm{~J}=7.6 \mathrm{~Hz}, 2 \mathrm{H}), 4.57-4.48(\mathrm{~m}, 2 \mathrm{H}), 4.02(\mathrm{t}, \mathrm{J}=8.6 \mathrm{~Hz}, 2 \mathrm{H}), 3.80(\mathrm{dd}, \mathrm{J}=8.8,5.1 \mathrm{~Hz}$, $2 \mathrm{H}), 3.30-3.19(\mathrm{~m}, 1 \mathrm{H}), 1.51-1.46(\mathrm{~m}, 3 \mathrm{H}), 1.45-1.41(\mathrm{~m}, 9 \mathrm{H})$

Preparation of 1-((1-(tert-butoxycarbonyl)azetidin-3-yl)methyl)-1H-indazole-3-carboxylic acid (S-3): 
A mixture of ethyl 1-((1-(tert-butoxycarbonyl)azetidin-3-yl)methyl)-1H-indazole-3-carboxylate (2.77 g, $7.71 \mathrm{mmol})$ and lithium hydroxide $(0.554 \mathrm{~g}, 23.12 \mathrm{mmol})$ in $\mathrm{MeOH}(17.13 \mathrm{ml})$ was stirred at $\mathrm{rt}$ for 16 hours. The reaction was quenched with acetic acid, diluted with water and transferred to a seperatory funnel. The aqueous layer was washed with EtOAc (3x). The organic layers were concentrated to afford 1-((1-(tert-butoxycarbonyl)azetidin-3-yl)methyl)-1H-indazole-3-carboxylic acid (S-3) $(2.5 \mathrm{~g}, 7.54 \mathrm{mmol}$, $98 \%$ yield). ${ }^{1} \mathrm{H}$ NMR (400MHz, CHLOROFORM-d) $\delta 8.30$ (d, J=8.2 Hz, 1H), $7.58-7.49(\mathrm{~m}, 2 \mathrm{H}), 7.40$ (ddd, $J=8.1,6.5,1.3 \mathrm{~Hz}, 1 \mathrm{H}), 4.71(\mathrm{~d}, J=7.6 \mathrm{~Hz}, 2 \mathrm{H}), 4.11-4.05(\mathrm{~m}, 2 \mathrm{H}), 3.85(\mathrm{dd}, J=8.9,5.1 \mathrm{~Hz}, 2 \mathrm{H}), 3.38-3.25$ (m, 1H), $1.48-1.45(\mathrm{~m}, 9 \mathrm{H})$.

Preparation of 6-(4-amino-2-chlorophenyl)pyridazin-3(2H)-one (S-4):

3-chloro-4-(4,4,5,5-tetramethyl-1,3,2-dioxaborolan-2-yl)aniline (0.364 g, $1.436 \mathrm{mmol}), 6$ chloropyridazin-3(2H)-one (S-3) $(0.150 \mathrm{~g}, 1.149 \mathrm{mmol})$, and $\mathrm{PdCl}_{2}(\mathrm{dppf})-\mathrm{DCM}$ adduct (0.094 g, 0.115 $\mathrm{mmol}$ ) were placed in a pressure vial and placed under vacuum. The vial was backfilled with nitrogen, then this process was repeated twice more. Dioxane $(5.75 \mathrm{ml})$ and tripotassium phosphate $(2 \mathrm{M}$ aqueous) (1.724 ml, $3.45 \mathrm{mmol}$ ) were added, then the reaction was heated to $100^{\circ} \mathrm{C}$ overnight. The reaction was cooled, diluted with EtOAc and water, and filtered. The reaction was extracted twice with EtOAc, then the organic layers were washed with brine, dried with sodium sulfate, and concentrated. The solid was triturated with DCM to give 6-(4-amino-2-chlorophenyl)pyridazin-3(2H)-one (S-4) $(0.088 \mathrm{~g}$, $0.397 \mathrm{mmol}, 34.6 \%$ yield). ${ }^{1} \mathrm{H}$ NMR (400MHz, DMSO-d $\left.\mathrm{d}_{6}\right) \delta 13.07$ (br s, $\left.1 \mathrm{H}\right), 7.58(\mathrm{~d}, J=9.8 \mathrm{~Hz}, 1 \mathrm{H}), 7.17$ (d, J=8.3 Hz, 1H), $6.87(\mathrm{~d}, J=9.8 \mathrm{~Hz}, 1 \mathrm{H}), 6.69(\mathrm{~d}, J=2.2 \mathrm{~Hz}, 1 \mathrm{H}), 6.58(\mathrm{dd}, J=8.4,2.2 \mathrm{~Hz}, 1 \mathrm{H}), 5.71(\mathrm{~s}, 2 \mathrm{H})$. Preparation of (tert-butyl 3-((3-((3-chloro-4-(6-oxo-1,6-dihydropyridazin-3-yl)phenyl)carbamoyl)-1Hindazol-1-yl)methyl)azetidine-1-carboxylate (S-5).

To a suspension of 1-((1-(tert-butoxycarbonyl)azetidin-3-yl)methyl)-1H-indazole-3-carboxylic acid $(0.063$ $\mathrm{g}, 0.189 \mathrm{mmol})(\mathbf{S}-3)$ and 6-(4-amino-2-chlorophenyl)pyridazin-3(2H)-one (S-4) $(0.035 \mathrm{~g}, 0.158 \mathrm{mmol})$ in DMF $(1.053 \mathrm{ml})$ was added PyBOP $(0.164 \mathrm{~g}, 0.316 \mathrm{mmol})$ and Hunig'sBase $(0.083 \mathrm{ml}, 0.474 \mathrm{mmol})$. The reaction was stirred overnight. The reaction was diluted with water and extracted with EtOAc. The organic layer was washed with $10 \% \mathrm{LiCl}$ solution, dried with sodium sulfate, and concentrated. The residue was purified via ISCO ( $12 \mathrm{~g}$ column; DCM/EtOAc; 0 to $100 \%$ gradient) to give tert-butyl 3-((3-)((3chloro-4-(6-oxo-1,6-dihydropyridazin-3-yl)phenyl)carbamoyl)-1H-indazol-1-yl)methyl)azetidine-1carboxylate (S-5) (36 mg of product containing 0.15 equivalents of aniline starting material) which was taken forward directly to the next reaction.

Preparation of 1-(azetidin-3-ylmethyl)-N-(3-chloro-4-(6-oxo-1,6-dihydropyridazin-3-yl)phenyl)-1Hindazole-3-carboxamide (TFA salt) (S-6):

To a suspension of tert-butyl 3-((3-((3-chloro-4-(6-oxo-1,6-dihydropyridazin-3-yl)phenyl)carbamoyl)-1Hindazol-1-yl)methyl)azetidine-1-carboxylate (S-6) $(0.024 \mathrm{~g}, 0.045 \mathrm{mmol})$ in DCM $(0.6 \mathrm{~mL})$ was added TFA $(0.15 \mathrm{~mL})$. Suspended material dissolved upon addition of TFA. After ca. 1 hour, the reaction was concentrated, then azeotroped with DCM and toluene to give 1-(azetidin-3-ylmethyl)-N-(3-chloro-4-(6oxo-1,6-dihydropyridazin-3-yl)phenyl)-1H-indazole-3-carboxamide, TFA(S-6): (0.027 g, 0.049 mmol, 110 $\%$ yield). LCMS RT: 0.66 min (Method $A$ ). $M / Z=435.2$.

Preparation of 1-((1-(tert-butylcarbamoyl)azetidin-3-yl)methyl)-N-(3-chloro-4-(6-oxo-1,6dihydropyridazin-3-yl)phenyl)-1H-indazole-3-carboxamide (1):

To a suspension of 1-(azetidin-3-ylmethyl)-N-(3-chloro-4-(6-oxo-1,6-dihydropyridazin-3-yl)phenyl)-1Hindazole-3-carboxamide, TFA $(12.08 \mathrm{mg}, 0.022 \mathrm{mmol})$ in DCM $(0.3 \mathrm{~mL})$ was added Hunig'sBase $(9.61 \mu \mathrm{l}$, $0.055 \mathrm{mmol}$ ) and 2-isocyanato-2-methylpropane ( $3.77 \mu \mathrm{l}, 0.033 \mathrm{mmol})$. After ca. 3 hours, the reaction was concentrated. The residue was dissolved in DMF. The crude material was purified via preparative LC/MS with the following conditions: Column: Waters XBridge C18, $19 \times 200 \mathrm{~mm}, 5-\mu \mathrm{m}$ particles; Mobile Phase A: 5:95 acetonitrile: water with 10-mM ammonium acetate; Mobile Phase B: 95:5 acetonitrile: water with 10-mM ammonium acetate; Gradient: 15-70\% B over 20 minutes, then a 5-minute hold at 100\% B; Flow: $20 \mathrm{~mL} / \mathrm{min}$. Fractions containing the desired product were combined and dried via 
centrifugal evaporation to give 1-((1-(tert-butylcarbamoyl)azetidin-3-yl)methyl)-N-(3-chloro-4-(6-oxo1,6-dihydropyridazin-3-yl)phenyl)-1H-indazole-3-carboxamide (1) (6.2 mg, 53\%).

LCMS RT: $1.58 \mathrm{~min}$ (Method B). M/Z= 533.2. Purity: 100\%. ${ }^{1} \mathrm{H}$ NMR (500MHz, DMSO-d 6 ) $\delta 13.35$ (s, $1 \mathrm{H}), 10.61(\mathrm{~s}, 1 \mathrm{H}), 8.26-8.16(\mathrm{~m}, 2 \mathrm{H}), 7.94(\mathrm{br} \mathrm{d}, J=8.5 \mathrm{~Hz}, 1 \mathrm{H}), 7.89(\mathrm{~d}, J=8.6 \mathrm{~Hz}, 1 \mathrm{H}), 7.71(\mathrm{~d}, J=9.8 \mathrm{~Hz}$, 1H), $7.60-7.49(\mathrm{~m}, 2 \mathrm{H}), 7.36(\mathrm{t}, J=7.5 \mathrm{~Hz}, 1 \mathrm{H}), 6.98(\mathrm{~d}, J=9.8 \mathrm{~Hz}, 1 \mathrm{H}), 5.62(\mathrm{~s}, 1 \mathrm{H}), 4.76(\mathrm{br} \mathrm{d}, J=7.2 \mathrm{~Hz}$, $2 \mathrm{H}), 3.84(\mathrm{t}, \mathrm{J}=8.2 \mathrm{~Hz}, 1 \mathrm{H}), 3.75-3.66(\mathrm{~m}, 1 \mathrm{H}), 3.62(\mathrm{br} \mathrm{s}, 2 \mathrm{H}), 3.19-3.07(\mathrm{~m}, 1 \mathrm{H}), 1.19(\mathrm{~s}, 9 \mathrm{H})$ Preparation of Compound 2:

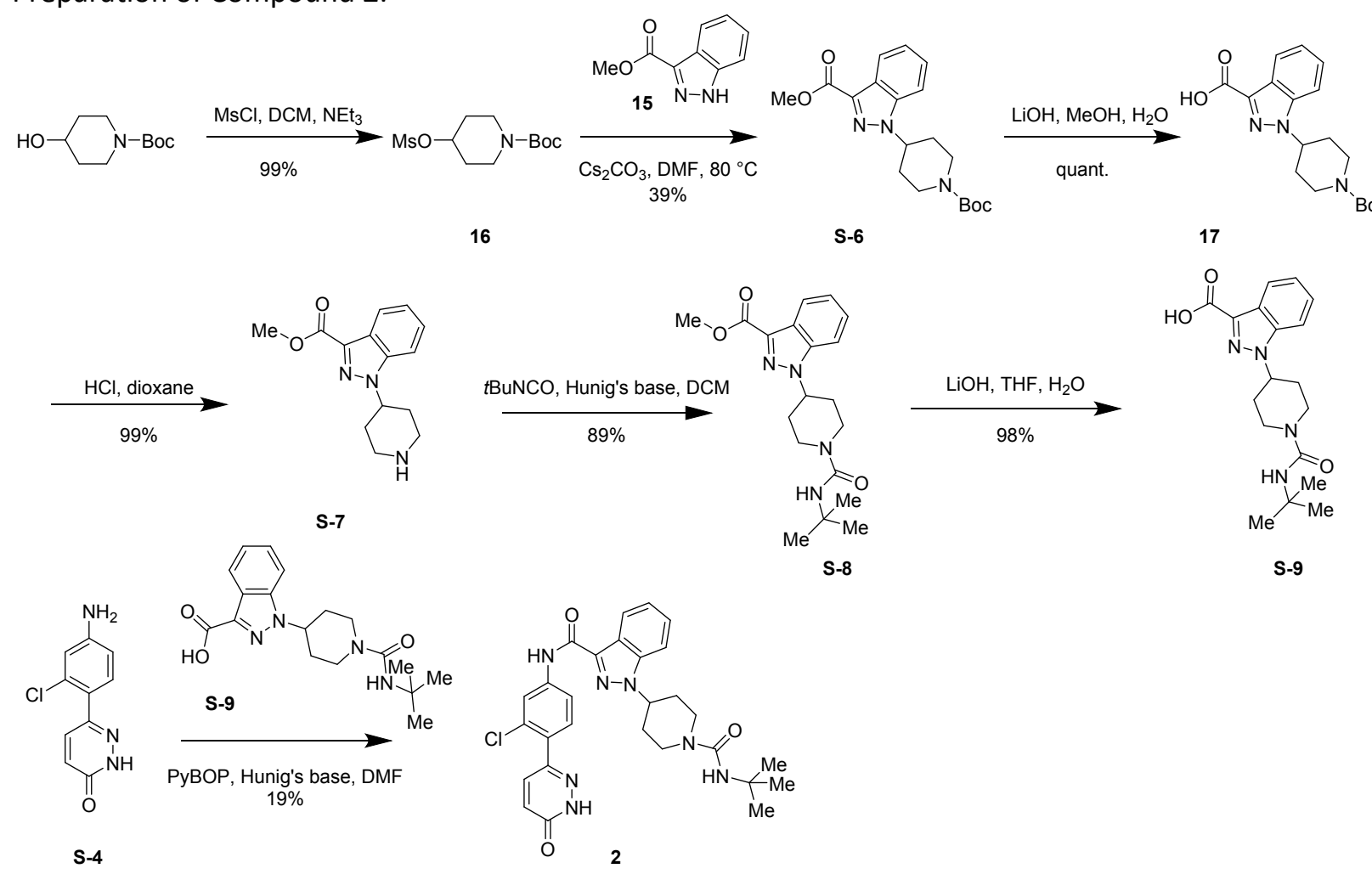

Preparation of tert-butyl 4-((methylsulfonyl)oxy)piperidine-1-carboxylate (16):

Tert-butyl 4-hydroxypiperidine-1-carboxylate $(5 \mathrm{~g}, 24.84 \mathrm{mmol})$ and $\mathrm{Et}_{3} \mathrm{~N}(5.19 \mathrm{ml}, 37.3 \mathrm{mmol})$ were dissolved in DCM $(10 \mathrm{~mL})$ and cooled to $0^{\circ} \mathrm{C}$ under $\mathrm{N}_{2}$. Methanesulfonyl chloride $(2.307 \mathrm{ml}, 29.8 \mathrm{mmol})$ was added and the reaction was stirred in an ice bath for 30 minutes, then stirred at $r$ for additional 2 hours. The mixture was diluted with $20 \mathrm{~mL}$ of water and $40 \mathrm{~mL}$ of DCM. The organic layer was washed with brine and dried over $\mathrm{Na}_{2} \mathrm{SO}_{4}$, then concentrated to afford tert-butyl 4-

((methylsulfonyl)oxy)piperidine-1-carboxylate (16) $\left(6.9 \mathrm{~g}, 24.70 \mathrm{mmol}, 99 \%\right.$ yield). ${ }^{1} \mathrm{H}$ NMR (400 MHz, CHLOROFORM-d) $\delta 4.89$ (tt, J=7.8, 3.8 Hz, 1H), 3.71 (ddd, J=13.3, 7.1, 3.9 Hz, 2H), 3.30 (ddd, J=13.7, 8.2, $3.8 \mathrm{~Hz}, 2 \mathrm{H}), 3.04(\mathrm{~s}, 3 \mathrm{H}), 2.02-1.92(\mathrm{~m}, 2 \mathrm{H}), 1.87-1.76(\mathrm{~m}, 2 \mathrm{H}), 1.46(\mathrm{~s}, 9 \mathrm{H})$.

Preparation of methyl 1-(1-(tert-butoxycarbonyl)piperidin-4-yl)-1H-indazole-3-carboxylate (S-6): A solution of methyl $1 \mathrm{H}$-indazole-3-carboxylate $(3 \mathrm{~g}, 17.03 \mathrm{mmol}), \mathrm{Cs}_{2} \mathrm{CO}_{3}(11.65 \mathrm{~g}, 35.8 \mathrm{mmol})$ and tertbutyl 4-((methylsulfonyl)oxy)piperidine-1-carboxylate (16) $(6.66 \mathrm{~g}, 23.84 \mathrm{mmol})$ in DMF (56.8 $\mathrm{ml})$ was stirred at $80^{\circ} \mathrm{C}$ for $3 \mathrm{~h}$. The reaction was diluted with $40 \mathrm{~mL}$ water. The aqueous layer was extracted with EtOAc. The organic layer was separated and concentrated. The residue was purified by ISCO (120 g column, $0 \rightarrow 50 \%$ EtOAc in hexanes) to afford methyl 1-(1-(tert-butoxycarbonyl)piperidin-4-yl)-1Hindazole-3-carboxylate (S-6): $(2.4 \mathrm{~g}, 6.68 \mathrm{mmol}, 39.2 \%$ yield). The desired regioisomer eluted after the undesired one. ${ }^{1} \mathrm{H}$ NMR $\left(400 \mathrm{MHz}\right.$, DMSO- $\left.\mathrm{d}_{6}\right) \mathrm{d} 8.15-8.07(\mathrm{~m}, 1 \mathrm{H}), 7.92(\mathrm{~d}, \mathrm{~J}=8.6 \mathrm{~Hz}, 1 \mathrm{H}), 7.56-7.47(\mathrm{~m}$, $1 \mathrm{H}), 7.37(\mathrm{td}, \mathrm{J}=7.6,0.7 \mathrm{~Hz}, 1 \mathrm{H}), 5.14-4.97(\mathrm{~m}, 1 \mathrm{H}), 4.23-4.07(\mathrm{~m}, 2 \mathrm{H}), 3.93(\mathrm{~s}, 3 \mathrm{H}), 3.15-2.86(\mathrm{~m}, 2 \mathrm{H})$, $2.00(\mathrm{~s}, 4 \mathrm{H}), 1.55-1.35(\mathrm{~m}, 9 \mathrm{H})$ 
Preparation of 1-(1-(tert-butoxycarbonyl)piperidin-4-yl)-1H-indazole-3-carboxylic acid (17): To a solution of ethyl 1-(1-(tert-butoxycarbonyl)piperidin-4-yl)-1H-indazole-3-carboxylate (S-6) (2.7 g, $7.23 \mathrm{mmol})$ in methanol $(21.69 \mathrm{ml})$ and water $(7.23 \mathrm{ml})$ was added lithium hydroxide, $\mathrm{H}_{2} \mathrm{O}(0.910 \mathrm{~g}$, $21.69 \mathrm{mmol})$. The reaction was heated to $65^{\circ} \mathrm{C}$. After ca. 2 hours, the reaction was cooled. The reaction was acidified with $1 \mathrm{M} \mathrm{HCl}$ and extracted twice with EtOAc. The organic layers were washed with brine and concentrated to give 1-(1-(tert-butoxycarbonyl)piperidin-4-yl)-1H-indazole-3-carboxylic acid (17) $\left(2.52 \mathrm{~g}, 7.30 \mathrm{mmol}, 101 \%\right.$ yield). ${ }^{1} \mathrm{H}$ NMR (400 MHz, DMSO-d 6 ) $\delta 8.17$ (d, J=7.9 Hz, $\left.1 \mathrm{H}\right), 7.78$ $7.66(\mathrm{~m}, 1 \mathrm{H}), 7.42-7.32(\mathrm{~m}, 1 \mathrm{H}), 7.26-7.15(\mathrm{~m}, 1 \mathrm{H}), 4.93-4.79(\mathrm{~m}, 1 \mathrm{H}), 4.20-4.07(\mathrm{~m}, 2 \mathrm{H}), 3.07$ - 2.90 $(\mathrm{m}, 2 \mathrm{H}), 2.02-1.88(\mathrm{~m}, 4 \mathrm{H}), 1.52-1.41(\mathrm{~m}, 9 \mathrm{H})$.

Preparation of methyl 1-(piperidin-4-yl)-1H-indazole-3-carboxylate, $\mathrm{HCl}(\mathbf{S}-7)$

Methyl 1-(1-(tert-butoxycarbonyl)piperidin-4-yl)-1H-indazole-3-carboxylate (17) (281 mg, $0.782 \mathrm{mmol})$ was dissolved in $4 \mathrm{M} \mathrm{HCl}$ in dioxane $(0.5 \mathrm{~mL})$ and stirred at $\mathrm{rt}$ for 3 hours. The reaction was concentrated followed by addition of ether. The resulting white precipitate was collected to afford methyl 1(piperidin-4-yl)-1H-indazole-3-carboxylate, $\mathrm{HCl}(\mathbf{S}-7)(229 \mathrm{mg}, 0.774 \mathrm{mmol}, 99 \%$ yield) as a desired product. ${ }^{1} \mathrm{H}$ NMR $\left(400 \mathrm{MHz}, \mathrm{DMSO}-\mathrm{d}_{6}\right) \delta 8.13-8.08(\mathrm{~m}, 1 \mathrm{H}), 7.91(\mathrm{~d}, J=8.6 \mathrm{~Hz}, 1 \mathrm{H}), 7.54$ (ddd, J=8.4, 7.0, $1.0 \mathrm{~Hz}, 1 \mathrm{H}), 7.42-7.35(\mathrm{~m}, 1 \mathrm{H}), 5.21-5.11(\mathrm{~m}, 1 \mathrm{H}), 3.93(\mathrm{~s}, 3 \mathrm{H}), 3.51-3.42(\mathrm{~m}, 2 \mathrm{H}), 3.22-3.08(\mathrm{~m}, 2 \mathrm{H})$, $2.42-2.29(\mathrm{~m}, 2 \mathrm{H}), 2.18(\mathrm{br} \mathrm{d}, J=11.2 \mathrm{~Hz}, 2 \mathrm{H})$.

Preparation of methyl 1-(1-(tert-butylcarbamoyl)piperidin-4-yl)-1H-indazole-3-carboxylate (S-8): To a suspension of methyl 1-(piperidin-4-yl)-1H-indazole-3-carboxylate, $\mathrm{HCl}(\mathrm{S}-7)(229 \mathrm{mg}, 0.774 \mathrm{mmol})$ in DCM $(1.9 \mathrm{~mL})$ was added Hunig'sBase $(811 \mu \mathrm{l}, 4.65 \mathrm{mmol})$ and 2-isocyanato-2-methylpropane (133 $\mu \mathrm{l}$, $1.161 \mathrm{mmol})$. The reaction was stirred at $\mathrm{rt}$ for $3 \mathrm{~h}$. The solvent was evaporated and the residue purified by ISCO (12 g column, $0 \rightarrow 80 \%$ EtOAc in Hexane) to afford methyl 1-(1-(tert-butylcarbamoyl)piperidin4-yl)-1H-indazole-3-carboxylate $(247 \mathrm{mg}, 0.689 \mathrm{mmol}, 89 \%$ yield) (S-8) as a white solid. LCMS RT: 0.88 $\min ($ Method $A) . M / Z=359.3$.

Preparation of 1-(1-(tert-butylcarbamoyl)piperidin-4-yl)-1H-indazole-3-carboxylic acid (S-9):

A mixture of methyl 1-(1-(tert-butylcarbamoyl)piperidin-4-yl)-1H-indazole-3-carboxylate (247 mg, 0.689 $\mathrm{mmol}$ ) and lithium hydroxide $(49.5 \mathrm{mg}, 2.067 \mathrm{mmol})$ in $\mathrm{MeOH}(3132 \mu \mathrm{l})$ and Water (313 $\mu \mathrm{l})$ was stirred at $r t$ for 3 days. The reaction was concentrated, quenched with citric acid, diluted with water and transferred to a seperatory funnel. The aqueous layer was washed with EtOAc (3x). The organic layer was separated and concentrated to afford 1-(1-(tert-butylcarbamoyl)piperidin-4-yl)-1H-indazole-3carboxylic acid ( $233 \mathrm{mg}, 0.677 \mathrm{mmol}, 98 \%$ yield) as the desired product. LC/MS RT: $0.77 \mathrm{~min}$ (Method A). $M / Z=345.3$.

Preparation of 1-(1-(tert-butylcarbamoyl)piperidin-4-yl)-N-(3-chloro-4-(6-oxo-1,6-dihydropyridazin-3yl)phenyl)-1H-indazole-3-carboxamide (2):

To a suspension of 1-(1-(tert-butylcarbamoyl)piperidin-4-yl)-1H-indazole-3-carboxylic acid (S-9) (0.016 g, $0.045 \mathrm{mmol})$ and 6-(4-amino-2-chlorophenyl)pyridazin-3(2H)-one (S-4) $(0.010 \mathrm{~g}, 0.045 \mathrm{mmol})$ in DMF $(0.3 \mathrm{~mL})$ was added Hunig'sBase $(0.024 \mathrm{~mL}, 0.135 \mathrm{mmol})$ and PyBOP $(0.029 \mathrm{~g}, 0.056 \mathrm{mmol})$. The reaction was stirred overnight, then $15 \mathrm{mg}$ PyBOP was added. After a further three hours, the reaction was diluted with DMF, filtered through a syringe filter, and purified via preparative LC/MS with the following conditions: Column: XBridge C18, $19 \times 200 \mathrm{~mm}, 5-\mu \mathrm{m}$ particles; Mobile Phase A: 5:95 acetonitrile: water with 10-mM ammonium acetate; Mobile Phase B: 95:5 acetonitrile: water with 10mM ammonium acetate; Gradient: $30-68 \%$ B over 20 minutes, then a 5-minute hold at $100 \%$ B; Flow: 20 $\mathrm{mL} / \mathrm{min}$. Fractions containing the desired product were combined and dried via centrifugal evaporation to give 1-(1-(tert-butylcarbamoyl)piperidin-4-yl)-N-(3-chloro-4-(6-oxo-1,6-dihydropyridazin-3-yl)phenyl)$1 \mathrm{H}$-indazole-3-carboxamide (2) (4.9 mg, 19\%).

LC/MS RT: 1.76 min (Method C) M/Z= 548.1 Purity 96.2\%. ${ }^{1} \mathrm{H}$ NMR (500MHz, DMSO-d $\left.\mathrm{d}_{6}\right) \delta 13.31$ (br s, 1H), $10.44(\mathrm{~s}, 1 \mathrm{H}), 8.28-8.15(\mathrm{~m}, 2 \mathrm{H}), 7.97(\mathrm{br} \mathrm{d}, J=8.2 \mathrm{~Hz}, 1 \mathrm{H}), 7.91(\mathrm{br} \mathrm{d}, J=8.5 \mathrm{~Hz}, 1 \mathrm{H}), 7.71$ (d, J=9.8 $\mathrm{Hz}, 1 \mathrm{H}), 7.60-7.45(\mathrm{~m}, 2 \mathrm{H}), 7.35(\mathrm{t}, J=7.5 \mathrm{~Hz}, 1 \mathrm{H}), 6.97(\mathrm{br} \mathrm{d}, J=9.8 \mathrm{~Hz}, 1 \mathrm{H}), 5.89(\mathrm{~s}, 1 \mathrm{H}), 4.97$ (br t, J=11.4 
$\mathrm{Hz}, 1 \mathrm{H}$ ), 4.20 (br d, J=12.7 Hz, 2H), 2.90 (br t, J=12.3 Hz, 2H), $2.23-2.08(\mathrm{~m}, 2 \mathrm{H}), 1.98$ (br d, J=10.5 Hz, $2 \mathrm{H}), 1.28(\mathrm{~s}, 9 \mathrm{H})$.

Preparation of Compound 3:

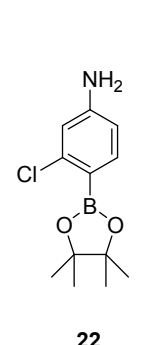

22

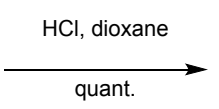

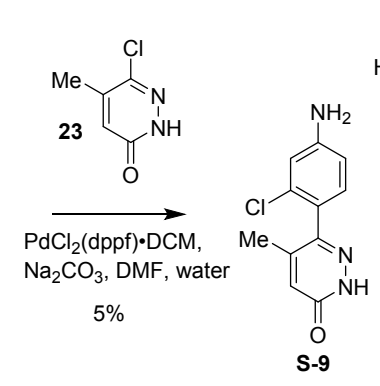

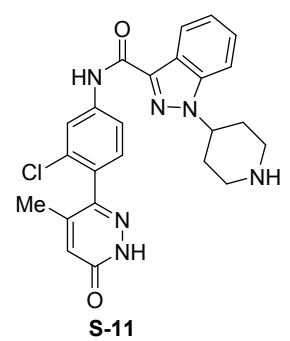

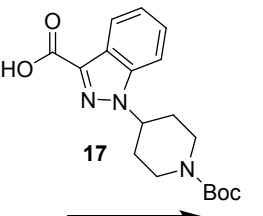

PyBop, $\mathrm{PPr}_{2} \mathrm{NEt}$ DMF, $50 \%$
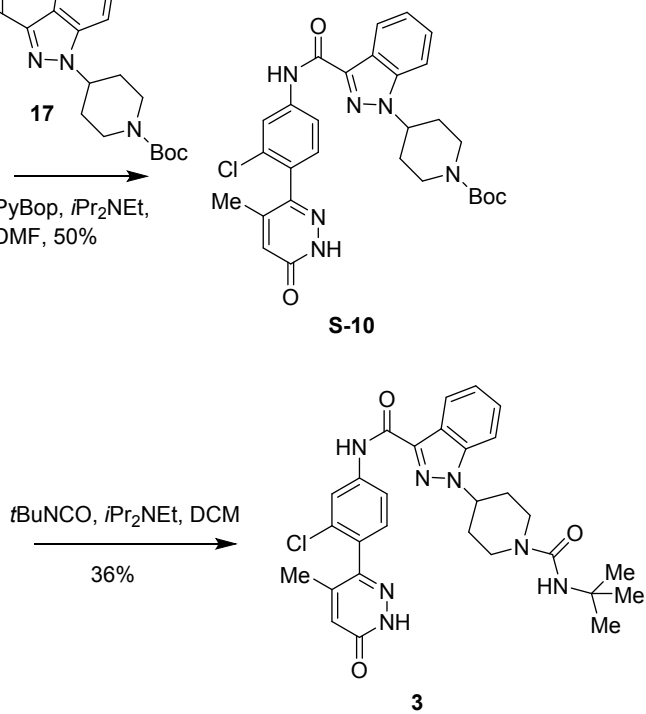

Preparation of 6-(4-amino-2-chlorophenyl)-5-methylpyridazin-3(2H)-one (S-9):

6-chloro-5-methylpyridazin-3(2H)-one (150 mg, 1.038 mmol), 3-chloro-4-(4,4,5,5-tetramethyl-1,3,2dioxaborolan-2-yl)aniline (289 mg, $1.141 \mathrm{mmol}$ ), and $\mathrm{PdCl}_{2}$ (dppf)-DCM adduct ( $85 \mathrm{mg}, 0.104 \mathrm{mmol}$ ) were placed in a pressure vial. The vial was degassed with nitrogen three times. DMF $(6918 \mu \mathrm{l})$ and sodium carbonate ( $2 \mathrm{M}$ aqueous) $(1556 \mu \mathrm{l}, 3.11 \mathrm{mmol}$ ) were added and the reaction was heated to 100 ${ }^{\circ} \mathrm{C}$ for $16 \mathrm{~h}$. The reaction mixture was transferred to a separatory funnel containing saturated aqueous $\mathrm{NaHCO}_{3}$ solution $(15 \mathrm{~mL})$. The aqueous layer was extracted with ethyl acetate $(3 \times 15 \mathrm{~mL})$. The combined organic layers were washed with brine $(15 \mathrm{~mL})$, dried over $\mathrm{MgSO}_{4}$, filtered, and concentrated. The residue was purified by ISCO ( $0 \% \rightarrow 100 \%$ ethyl acetate in hexanes; $24 \mathrm{~g}$ column) to afford 6 -(4amino-2-chlorophenyl)-5-methylpyridazin-3(2H)-one (S-9) (11 mg, $0.047 \mathrm{mmol}, 4.50 \%$ yield). LC/MS RT: $0.58 \mathrm{~min}$ (Method A). $M / Z=236.0$.

Preparation of tert-butyl 4-(3-((3-chloro-4-(4-methyl-6-oxo-1,6-dihydropyridazin-3yl)phenyl)carbamoyl)-1H-indazol-1-yl)piperidine-1-carboxylate (S-10):

To a suspension of 1-(1-(tert-butoxycarbonyl)piperidin-4-yl)-1H-indazole-3-carboxylic acid (19.05 mg, $0.055 \mathrm{mmol})$ and 6-(4-amino-2-chlorophenyl)-5-methylpyridazin-3(2H)-one (S-9) $(10 \mathrm{mg}, 0.042 \mathrm{mmol})$ in DMF $(283 \mu \mathrm{l})$ was added PyBOP $(44.2 \mathrm{mg}, 0.085 \mathrm{mmol})$ and Hunig's Base $(22.23 \mu \mathrm{l}, 0.127 \mathrm{mmol})$. The reaction was stirred at $\mathrm{rt}$ for $16 \mathrm{~h}$. The reaction was diluted with water and extracted twice with EtOAc. The organic layer was washed with $10 \% \mathrm{LiCl}$ solution, dried with sodium sulfate, and concentrated. The residue was purified via reverse phase HPLC ( water:MeOH) to give tert-butyl 4-(3-((3-chloro-4-(4methyl-6-oxo-1,6-dihydropyridazin-3-yl)phenyl)carbamoyl)-1H-indazol-1-yl)piperidine-1-carboxylate (S10) (12 mg, $0.021 \mathrm{mmol}, 50.2 \%$ yield). LC/MS RT: $1.09 \mathrm{~min}$ (Method A). M/Z=563.3.

Preparation of N-(3-chloro-4-(4-methyl-6-oxo-1,6-dihydropyridazin-3-yl)phenyl)-1-(piperidin-4-yl)-1Hindazole-3-carboxamide, $\mathrm{HCl}(\mathbf{S}-\mathbf{1 1})$ :

$\mathrm{HCl}$ (4M in Dioxane) $(160 \mu \mathrm{l}, 0.639 \mathrm{mmol})$ was added to tert-butyl 4-(3-((3-chloro-4-(4-methyl-6-oxo-1,6dihydropyridazin-3-yl)phenyl)carbamoyl)-1H-indazol-1-yl)piperidine-1-carboxylate (S-10) (12 mg, 0.021 $\mathrm{mmol}$ ) in a vial. The reaction was stirred at $\mathrm{rt}$ for $3 \mathrm{~h}$. The reaction was concentrated, triturated with ether and filtered to give $\mathrm{N}$-(3-chloro-4-(4-methyl-6-oxo-1,6-dihydropyridazin-3-yl)phenyl)-1-(piperidin4-yl)-1H-indazole-3-carboxamide, $\mathrm{HCl}$ (S-11) $(10.5 \mathrm{mg}, 0.021 \mathrm{mmol}, 99 \%$ yield), which was taken on directly to the next step. LC/MS RT: $0.74 \mathrm{~min}$ (Method A). M/Z=463.3. 
Preparation of 1-(1-(tert-butylcarbamoyl)piperidin-4-yl)-N-(3-chloro-4-(4-methyl-6-oxo-1,6dihydropyridazin-3-yl)phenyl)-1H-indazole-3-carboxamide (3):

To a suspension of N-(3-chloro-4-(4-methyl-6-oxo-1,6-dihydropyridazin-3-yl)phenyl)-1-(piperidin-4-yl)$1 \mathrm{H}$-indazole-3-carboxamide, $\mathrm{HCl}(\mathbf{S}-11)(10 \mathrm{mg}, 0.020 \mathrm{mmol})$ in $\mathrm{DCM}(0.300 \mathrm{~mL})$ was added Hunig'sBase $(0.021 \mathrm{~mL}, 0.120 \mathrm{mmol})$ and 2-isocyanato-2-methylpropane $(3.43 \mu \mathrm{l}, 0.030 \mathrm{mmol})$. The reaction was stirred at $\mathrm{rt}$ for $3 \mathrm{~h}$. The solvent was evaporated and the residue was dissolved in $\mathrm{MeOH}$ and purified by reverse phase HPLC (Water:MeOH) to afford 1-(1-(tert-butylcarbamoyl)piperidin-4-yl)-N-(3-chloro-4-(4methyl-6-oxo-1,6-dihydropyridazin-3-yl)phenyl)-1H-indazole-3-carboxamide (3) (4.1 mg, 7.22 $\mu \mathrm{mol}, 36.1$ $\%$ yield).

HPLC RT: 23.87 min (Method A) M/Z=562.3 Purity 95.4\%. ${ }^{1} \mathrm{H}$ NMR (400MHz, METHANOL- $\mathrm{d}_{4}$ ) ? 8.32 (d, $J=8.2 \mathrm{~Hz}, 1 \mathrm{H}), 8.20(\mathrm{~d}, J=2.1 \mathrm{~Hz}, 1 \mathrm{H}), 7.83(\mathrm{dd}, J=8.5,2.1 \mathrm{~Hz}, 1 \mathrm{H}), 7.79(\mathrm{~d}, J=8.7 \mathrm{~Hz}, 1 \mathrm{H}), 7.65(\mathrm{~d}, J=1.2 \mathrm{~Hz}$, $1 \mathrm{H}), 7.55(\mathrm{~d}, J=8.3 \mathrm{~Hz}, 1 \mathrm{H}), 7.52(\mathrm{~d}, J=1.1 \mathrm{~Hz}, 1 \mathrm{H}), 7.39-7.33(\mathrm{~m}, 1 \mathrm{H}), 5.02-4.93(\mathrm{~m}, 1 \mathrm{H}), 4.25(\mathrm{~d}, J=13.8$ Hz, 2H), 3.09 (t, J=11.9 Hz, 2H), 2.26 (d, J=1.2 Hz, 3H), 2.12 (d, J=12.2 Hz, 2H), 1.59 (br. s., 2H), 1.40 (s, $9 \mathrm{H}$ Preparation of Compound 4:
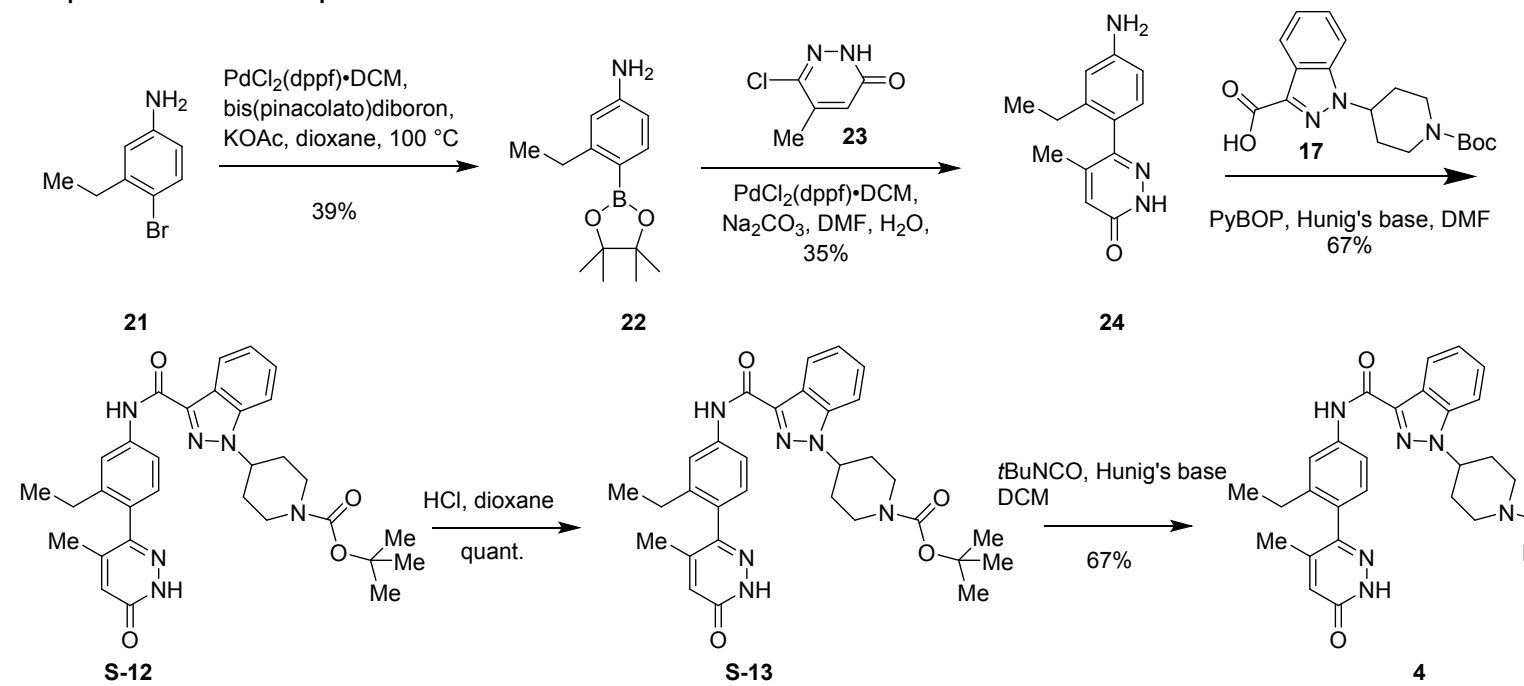

22

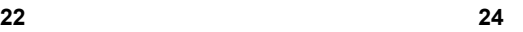

24

Preparation of 3-ethyl-4-(4,4,5,5-tetramethyl-1,3,2-dioxaborolan-2-yl)aniline (22):

A vial containing 4-bromo-3-ethylaniline ( $2.0 \mathrm{~g}, 10.00 \mathrm{mmol}), \mathrm{PdCl}_{2}(\mathrm{dppf})-\mathrm{DCM}$ adduct $(0.245 \mathrm{~g}, 0.300$ $\mathrm{mmol})$, bis(pinacolato)diboron $(6.35 \mathrm{~g}, 24.99 \mathrm{mmol})$, and potassium acetate $(2.94 \mathrm{~g}, 30.0 \mathrm{mmol})$ was placed under vacuum and backfilled with nitrogen three times. Dioxane $(50.0 \mathrm{ml})$ was added and the reaction was heated to $100^{\circ} \mathrm{C}$. After three hours, the reaction was cooled and filtered. The filtrate was concentrated. The residue was purified via ISCO ( $40 \mathrm{~g}$ column; Hex/EtOAc; 0 to $30 \%$ gradient). Product eluted along with debrominated starting material; debrominated starting material was removed by washing with hexanes. 3-ethyl-4-(4,4,5,5-tetramethyl-1,3,2-dioxaborolan-2-yl)aniline (22) (0.970 g, 3.92 mmol, $39.3 \%$ yield) was obtained. ${ }^{1} \mathrm{H}$ NMR (400 MHz, CHLOROFORM-d) $\delta 7.62$ (d, $\left.J=7.8 \mathrm{~Hz}, 1 \mathrm{H}\right), 6.53$ $6.47(\mathrm{~m}, 2 \mathrm{H}), 3.76$ (br s, 2H), 2.84 (q, J=7.5 Hz, 2H), $1.35-1.30(\mathrm{~m}, 12 \mathrm{H}), 1.18(\mathrm{t}, J=7.5 \mathrm{~Hz}, 3 \mathrm{H})$ Preparation of 6-(4-amino-2-ethylphenyl)-5-methylpyridazin-3(2H)-one (24):

6-chloro-5-methylpyridazin-3(2H)-one (0.400 g, $2.77 \mathrm{mmol})$, 3-ethyl-4-(4,4,5,5-tetramethyl-1,3,2dioxaborolan-2-yl)aniline (22) $(0.752 \mathrm{~g}, 3.04 \mathrm{mmol})$, and $\mathrm{PdCl}_{2}(\mathrm{dppf})$-DCM adduct $(0.226 \mathrm{~g}, 0.277 \mathrm{mmol})$ were placed in a pressure vial. The vial was placed under vacuum and backfilled with nitrogen three times. DMF (18.45 $\mathrm{ml}$ ) and sodium carbonate (2M aqueous) $(6.92 \mathrm{ml}, 13.84 \mathrm{mmol})$ were added and the reaction was heated to $100^{\circ} \mathrm{C}$. Reaction became very thick; $5 \mathrm{~mL}$ additional DMF was added. The reaction was transferred to a larger flask with a larger stirring bar to enable stirring, then heated overnight. The reaction was partially concentrated, diluted with water, and extracted three times with EtOAc. The organic layer was washed with $10 \% \mathrm{LiCl}$ solution, dried with sodium sulfate, and 
concentrated. The residue was purified via ISCO ( $120 \mathrm{~g}$ column; DCM/MeOH; 0 to $8 \%$ gradient) to give 6-(4-amino-2-ethylphenyl)-5-methylpyridazin-3(2H)-one (24) $(0.224 \mathrm{~g}, 0.977 \mathrm{mmol}, 35.3 \%$ yield).

LC/MS RT: 0.49 min (Method A). M/Z= 230.0.

Preparation of tert-butyl 4-(3-((3-ethyl-4-(4-methyl-6-oxo-1,6-dihydropyridazin-3-yl)phenyl)carbamoyl)1H-indazol-1-yl)piperidine-1-carboxylate (S-12):

To a solution of 1-(1-(tert-butoxycarbonyl)piperidin-4-yl)-1H-indazole-3-carboxylic acid (17) $(0.030 \mathrm{~g}$, $0.087 \mathrm{mmol}$ ) and 6-(4-amino-2-ethylphenyl)-5-methylpyridazin-3(2H)-one (24) $(0.016 \mathrm{~g}, 0.070 \mathrm{mmol})$ in DMF $(0.4 \mathrm{~mL})$ was added PyBOP $(0.058 \mathrm{~g}, 0.112 \mathrm{mmol})$ and Hunig'sBase $(0.037 \mathrm{~mL}, 0.209 \mathrm{mmol})$. After 4 hours, $15 \mathrm{mg}$ (17) and $30 \mathrm{mg}$ PyBOP were added. After ca. 2.5 hours, water was added and the precipitated solid was filtered off. The residue was purified via ISCO (12g column; Hex/EtOAc; 0 to $75 \%$ gradient, then $\mathrm{DCM} / \mathrm{MeOH} 0$ to $10 \%$ gradient) to give tert-butyl 4-(3-((3-ethyl-4-(4-methyl-6-oxo-1,6dihydropyridazin-3-yl)phenyl)carbamoyl)-1H-indazol-1-yl)piperidine-1-carboxylate (S-12) (0.026 g, 0.047 mmol, $66.9 \%$ yield). ${ }^{1} \mathrm{H}$ NMR (400 MHz, CHLOROFORM-d) $\delta \mathrm{ppm} 11.25(1 \mathrm{H}, \mathrm{br} \mathrm{s}), 8.91(1 \mathrm{H}, \mathrm{s}), 8.47$ (1 $\mathrm{H}, \mathrm{d}, J=8.19 \mathrm{~Hz}), 7.76(1 \mathrm{H}, \mathrm{d}, J=2.08 \mathrm{~Hz}), 7.72(1 \mathrm{H}, \mathrm{dd}, J=8.25,2.14 \mathrm{~Hz}), 7.44-7.55(2 \mathrm{H}, \mathrm{m}), 7.35(1 \mathrm{H}$, ddd, J=8.01, 6.79, $0.98 \mathrm{~Hz}), 7.17(1 \mathrm{H}, \mathrm{d}, J=8.19 \mathrm{~Hz}), 6.86(1 \mathrm{H}, \mathrm{d}, J=1.10 \mathrm{~Hz}), 4.67(1 \mathrm{H}, \mathrm{tt}, J=11.39,4.02$ $\mathrm{Hz}), 4.30$ - $4.46(2 \mathrm{H}, \mathrm{m}), 3.02(2 \mathrm{H}, \mathrm{brt}, J=12.29 \mathrm{~Hz}), 2.51(2 \mathrm{H}, \mathrm{q}, J=7.42 \mathrm{~Hz}), 2.25-2.40(2 \mathrm{H}, \mathrm{m}), 2.11(2$ $\mathrm{H}, \mathrm{br} d, J=11.37 \mathrm{~Hz}), 2.00(3 \mathrm{H}, \mathrm{d}, J=1.10 \mathrm{~Hz}), 1.53(9 \mathrm{H}, \mathrm{s}), 1.18(3 \mathrm{H}, \mathrm{t}, J=7.58 \mathrm{~Hz})$

Preparation of (N-(3-ethyl-4-(4-methyl-6-oxo-1,6-dihydropyridazin-3-yl)phenyl)-1-(piperidin-4-yl)-1Hindazole-3-carboxamide, $\mathrm{HCl}$ (S-13)

Tert-butyl 4-(3-((3-ethyl-4-(4-methyl-6-oxo-1,6-dihydropyridazin-3-yl)phenyl)carbamoyl)-1H-indazol-1yl)piperidine-1-carboxylate (S-12) $(0.328 \mathrm{~g}, 0.589 \mathrm{mmol})$ was suspended in $4 \mathrm{M} \mathrm{HCl}$ in dioxane $(5.89 \mathrm{ml})$. After 1.5 hours, the reaction was concentrated and dried under vacuum, then slurried with hexanes and dried under vacuum again. Weight still exceeds theoretical; compuound was used as $85 \%$ purity in next reaction. N-(3-ethyl-4-(4-methyl-6-oxo-1,6-dihydropyridazin-3-yl)phenyl)-1-(piperidin-4-yl)-1H-indazole3-carboxamide, $\mathrm{HCl}$ (S-13) (0.360 g, $0.621 \mathrm{mmol}, 105 \%$ yield) was obtained. LC/MS RT: $0.66 \mathrm{~min}$ (Method A). $M / Z=457.3$.

Preparation of (1-(1-(tert-butylcarbamoyl)piperidin-4-yl)-N-(3-ethyl-4-(4-methyl-6-oxo-1,6dihydropyridazin-3-yl)phenyl)-1H-indazole-3-carboxamide (4):

To a suspension of N-(3-ethyl-4-(4-methyl-6-oxo-1,6-dihydropyridazin-3-yl)phenyl)-1-(piperidin-4-yl)-1Hindazole-3-carboxamide, $\mathrm{HCl}(\mathbf{S}-13)$ (purity estimated as $85 \%)(0.175 \mathrm{~g}, 0.302 \mathrm{mmol}$ ) in DCM (3 mL) was added Hunig'sBase $(0.211 \mathrm{~mL}, 1.207 \mathrm{mmol})$ and tbutyl isocyanate $(0.052 \mathrm{~mL}, 0.453 \mathrm{mmol})$. Suspended material dissolved after the addition of the amine. After ca. 1 hour, the reaction was concentrated. A second reaction was run using the same conditions on an additional portion of S-13 $(0.090 \mathrm{~g}, 0.155$ $\mathrm{mmol}$ ). The reactions were combined and the residue was purified via ISCO ( 40g column; DCM/MeOH; 1 to $10 \%$ gradient). Mixed fractions were repurified using the same conditions to obtain 1-(1-(tertbutylcarbamoyl)piperidin-4-yl)-N-(3-ethyl-4-(4-methyl-6-oxo-1,6-dihydropyridazin-3-yl)phenyl)-1Hindazole-3-carboxamide (4) (169 $\mathrm{mg}, 0.301 \mathrm{mmol}, 51 \%$ yield from S-12)

HPLC RT: 8.88 min (Method B). Purity 99.1\%. ${ }^{1} \mathrm{H}$ NMR (400 MHz, METHANOL-d4) $\delta 8.31$ (d, J=8.2 Hz, $1 \mathrm{H}), 7.83(\mathrm{~d}, \mathrm{~J}=2.0 \mathrm{~Hz}, 1 \mathrm{H}$ ), 7.77 (dd, J=8.3, 2.4 Hz, 2H), 7.49 (ddd, J=8.4, 7.1, 1.0 Hz, 1H), 7.33 (t, J=7.6 Hz, $1 \mathrm{H}), 7.20(\mathrm{~d}, \mathrm{~J}=8.3 \mathrm{~Hz}, 1 \mathrm{H}), 6.91(\mathrm{~d}, \mathrm{~J}=1.2 \mathrm{~Hz}, 1 \mathrm{H}), 5.80(\mathrm{~s}, 1 \mathrm{H}), 4.93(\mathrm{tt}, \mathrm{J}=11.4,4.2 \mathrm{~Hz}, 1 \mathrm{H}), 4.23(\mathrm{br} \mathrm{d}$, $\mathrm{J}=13.6 \mathrm{~Hz}, 2 \mathrm{H}$ ), $3.14-3.00(\mathrm{~m}, 2 \mathrm{H}), 2.50(\mathrm{q}, \mathrm{J}=7.5 \mathrm{~Hz}, 2 \mathrm{H}), 2.30$ (qd, J=12.3, $4.1 \mathrm{~Hz}, 2 \mathrm{H}), 2.15$ - $2.05(\mathrm{~m}$, 2H), 2.02 (d, J=1.1 Hz, 3H), $1.38(\mathrm{~s}, 9 \mathrm{H}), 1.17(\mathrm{t}, \mathrm{J}=7.5 \mathrm{~Hz}, 3 \mathrm{H}) .{ }^{13} \mathrm{C}$ NMR (101 MHz, METHANOL-d $\left.\mathrm{d}_{4}\right) \delta$ 163.9, 163.2, 159.5, 151.0, 147.6, 144.9, 142.1, 140.6, 138.5, 131.6, 131.0, 128.9, 128.2, 124.4, 124.3, $123.4,122.0,119.3,111.2,57.8,51.9,44.5,32.8,29.9,27.6,20.0,15.7$. HRMS calculated for $\mathrm{C}_{31} \mathrm{H}_{38} \mathrm{O}_{3} \mathrm{~N}_{7}$ $(\mathrm{M}+\mathrm{H})$ 556.3031, found 556.3022.

Preparation of compound $\mathbf{5}$ : 

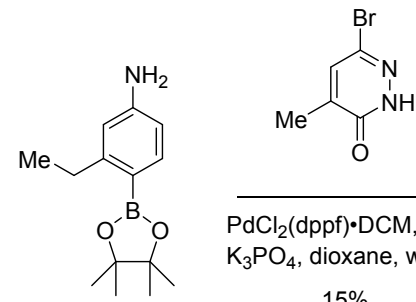

$\mathrm{PdCl}_{2}$ (dppf)・DCM,

$\mathrm{K}_{3} \mathrm{PO}_{4}$, dioxane, water

$15 \%$

22

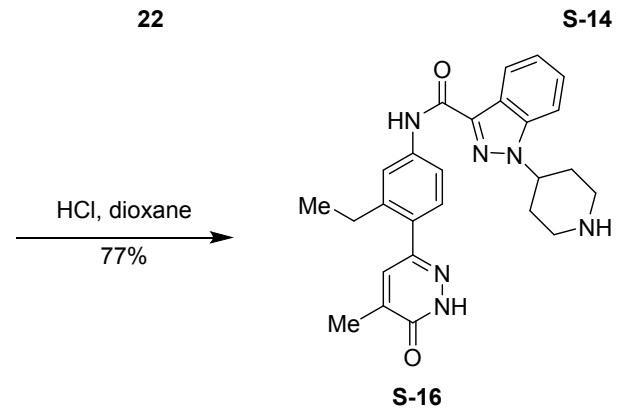

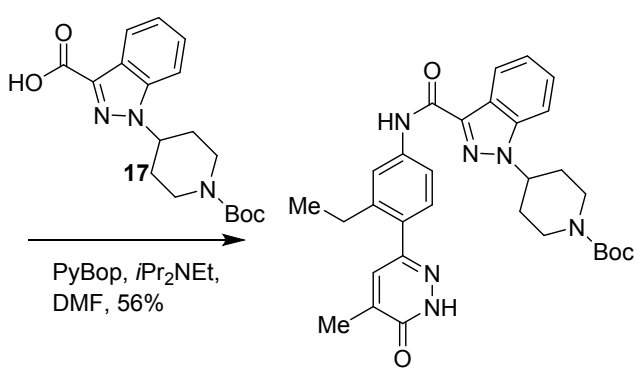

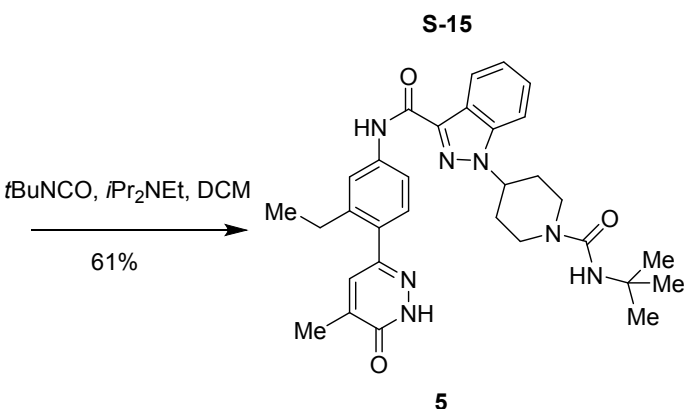

Preparation of (6-(4-amino-2-ethylphenyl)-4-methylpyridazin-3(2H)-one (S-14):

A vial containing 6-bromo-4-methylpyridazin-3(2H)-one $(0.075 \mathrm{~g}, 0.397 \mathrm{mmol})$, 3-ethyl-4- $(4,4,5,5-$ tetramethyl-1,3,2-dioxaborolan-2-yl)aniline (22) $(0.118 \mathrm{~g}, 0.476 \mathrm{mmol})$, and $\mathrm{PdCl}_{2}$ (dppf)-DCM adduct $(0.032 \mathrm{~g}, 0.040 \mathrm{mmol})$ was placed under vacuum and backfilled with nitrogen three times. Dioxane (3.97 $\mathrm{ml}$ ) and tripotassium phosphate ( $2 \mathrm{M}$ aqueous) $(0.595 \mathrm{ml}, 1.190 \mathrm{mmol}$ ) were added. Reaction was stirred overnight. tripotassium phosphate (2M aqueous) $\left(0.595 \mathrm{ml}, 1.190 \mathrm{mmol}\right.$ ) and $\mathrm{PdCl}_{2}$ (dppf)-DCM Adduct $(0.032 \mathrm{~g}, 0.040 \mathrm{mmol})$ were added and the reaction was heated to $100{ }^{\circ} \mathrm{C}$. After 8 hours, the reaction was cooled. The reaction was diluted with water and extracted twice with EtOAc. The organic layers were washed with brine, dried with sodium sulfate and concentrated. The residue was purified via ISCO (24g column; DCM/EtOAc; 0 to $100 \%$ gradient) to give 6-(4-amino-2-ethylphenyl)-4methylpyridazin-3(2H)-one (S-14) $\left(0.014 \mathrm{~g}, 0.061 \mathrm{mmol}, 15.39 \%\right.$ yield). ${ }^{1} \mathrm{H}$ NMR (400MHz, METHANOL$\left.\mathrm{d}_{4}\right) \delta 7.41(\mathrm{~d}, J=1.2 \mathrm{~Hz}, 1 \mathrm{H}), 7.07(\mathrm{~d}, J=8.2 \mathrm{~Hz}, 1 \mathrm{H}), 6.69(\mathrm{~d}, J=2.2 \mathrm{~Hz}, 1 \mathrm{H}), 6.64$ (dd, J=8.2, $\left.2.3 \mathrm{~Hz}, 1 \mathrm{H}\right), 2.63$ (q, J=7.5 Hz, 2H), 2.20 (d, J=1.2 Hz, 3H), $1.11(\mathrm{t}, J=7.6 \mathrm{~Hz}, 3 \mathrm{H})$.

Preparation of (tert-butyl 4-(3-((3-ethyl-4-(5-methyl-6-oxo-1,6-dihydropyridazin-3$\mathrm{yl}$ )phenyl)carbamoyl)-1H-indazol-1-yl)piperidine-1-carboxylate (S-15):

To a solution of 1-(1-(tert-butoxycarbonyl)piperidin-4-yl)-1H-indazole-3-carboxylic acid (17) $(0.027 \mathrm{~g}$, $0.079 \mathrm{mmol}$ ) and 6-(4-amino-2-ethylphenyl)-4-methylpyridazin-3(2H)-one (S-14) (0.014 g, $0.061 \mathrm{mmol})$ in DMF $(0.3 \mathrm{~mL})$ was added PyBOP $(0.048 \mathrm{~g}, 0.092 \mathrm{mmol})$ and Hunig'sBase $(0.032 \mathrm{~mL}, 0.183 \mathrm{mmol})$. The reaction was stirred overnight, then $13 \mathrm{mg}$ (17), $24 \mathrm{mg}$ PyBOP, and $30 \mu \mathrm{L}$ Hunig's base were added. After 6 hours, the reaction was diluted with water and extracted twice with EtOAc. The organic layer was concentrated. The residue was purified via ISCO ( $12 \mathrm{~g}$ column; Hex/EtOAc; 0 to $100 \%$ gradient) to give tert-butyl 4-(3-((3-ethyl-4-(5-methyl-6-oxo-1,6-dihydropyridazin-3-yl)phenyl)carbamoyl)-1Hindazol-1-yl)piperidine-1-carboxylate (S-15) $\left(0.019 \mathrm{~g}, 0.034 \mathrm{mmol}, 55.9 \%\right.$ yield). ${ }^{1} \mathrm{H}$ NMR $(400 \mathrm{MHz}$, CHLOROFORM-d) $\delta 11.00(\mathrm{~s}, 1 \mathrm{H}), 8.90(\mathrm{~s}, 1 \mathrm{H}), 8.47(\mathrm{~d}, \mathrm{~J}=8.2 \mathrm{~Hz}, 1 \mathrm{H}), 7.81$ - $7.67(\mathrm{~m}, 2 \mathrm{H}), 7.62$ - $7.44(\mathrm{~m}$, 2H), $7.41-7.31(\mathrm{~m}, 2 \mathrm{H}), 7.28(\mathrm{br} \mathrm{d}, J=1.1 \mathrm{~Hz}, 1 \mathrm{H}), 4.72-4.60(\mathrm{~m}, 1 \mathrm{H}), 4.39(\mathrm{br} \mathrm{s}, 2 \mathrm{H}), 3.01$ (br t, J=12.2 Hz, 2H), $2.76(\mathrm{q}, J=7.3 \mathrm{~Hz}, 2 \mathrm{H}), 2.29(\mathrm{~s}, 5 \mathrm{H}), 2.11(\mathrm{br} \mathrm{d}, J=11.1 \mathrm{~Hz}, 2 \mathrm{H}), 1.53(\mathrm{~s}, 9 \mathrm{H}), 1.24-1.18(\mathrm{~m}, 3 \mathrm{H})$. Preparation of N-(3-ethyl-4-(5-methyl-6-oxo-1,6-dihydropyridazin-3-yl)phenyl)-1-(piperidin-4-yl)-1Hindazole-3-carboxamide, $\mathrm{HCl}(\mathrm{S}-16)$ :

Tert-butyl 4-(3-((3-ethyl-4-(5-methyl-6-oxo-1,6-dihydropyridazin-3-yl)phenyl)carbamoyl)-1H-indazol-1yl)piperidine-1-carboxylate $(0.019 \mathrm{~g}, 0.034 \mathrm{mmol})(\mathrm{S}-15)$ was suspended in $4 \mathrm{M} \mathrm{HCl}$ in dioxane $(0.341 \mathrm{ml})$. After ca. 1 hour, Et2O was added, and the precipitated solid was filtered off, washed with Et2O, and 
dried to give N-(3-ethyl-4-(5-methyl-6-oxo-1,6-dihydropyridazin-3-yl)phenyl)-1-(piperidin-4-yl)-1Hindazole-3-carboxamide, $\mathrm{HCl}(0.013 \mathrm{~g}, 0.026 \mathrm{mmol}, 77 \%$ yield). LC/MS RT: $0.69 \mathrm{~min}$ (Method A). M/Z= 457.5.

Preparation of 1-(1-(tert-butylcarbamoyl)piperidin-4-yl)-N-(3-ethyl-4-(5-methyl-6-oxo-1,6dihydropyridazin-3-yl)phenyl)-1H-indazole-3-carboxamide (5):

To a suspension of N-(3-ethyl-4-(5-methyl-6-oxo-1,6-dihydropyridazin-3-yl)phenyl)-1-(piperidin-4-yl)-1Hindazole-3-carboxamide, $\mathrm{HCl}(\mathbf{S}-15)(0.013 \mathrm{~g}, 0.026 \mathrm{mmol})$ in dichloromethane $(0.300 \mathrm{~mL})$ was added Hunig'sBase $(0.014 \mathrm{~mL}, 0.079 \mathrm{mmol})$ and tbutyl isocyanate $(4.52 \mu \mathrm{l}, 0.040 \mathrm{mmol})$. After $45 \mathrm{minutes}$, the reaction was concentrated. The residue was dissolved in DMF, filtered through a syringe filter, The crude material was purified via preparative LC/MS with the following conditions: Column: XBridge C18, $19 \times 200 \mathrm{~mm}, 5-\mu \mathrm{m}$ particles; Mobile Phase A: 5:95 acetonitrile: water with 10-mM ammonium acetate; Mobile Phase B: 95:5 acetonitrile: water with 10-mM ammonium acetate; Gradient: 10-100\% B over 15 minutes, then a 5-minute hold at 100\% B; Flow: $20 \mathrm{~mL} / \mathrm{min}$. Fractions containing the desired product were combined and dried via centrifugal evaporation to give 1-(1-(tert-butylcarbamoyl)piperidin-4-yl)-N(3-ethyl-4-(5-methyl-6-oxo-1,6-dihydropyridazin-3-yl)phenyl)-1H-indazole-3-carboxamide (8.9 mg, 61\%). LC/MS RT: $1.79 \mathrm{~min}$ (Method B) M/Z= 556.2 Purity 100\%. ${ }^{1} \mathrm{H}$ NMR (500MHz, DMSO-d 6 ) $\delta 13.03(\mathrm{~s}, 1 \mathrm{H})$, $10.16(\mathrm{~s}, 1 \mathrm{H}), 8.23(\mathrm{br} \mathrm{d}, J=8.1 \mathrm{~Hz}, 1 \mathrm{H}), 7.98-7.79(\mathrm{~m}, 3 \mathrm{H}), 7.54-7.44(\mathrm{~m}, 2 \mathrm{H}), 7.38-7.20(\mathrm{~m}, 2 \mathrm{H}), 5.89$ (s, 1H), $4.95(\mathrm{brt}, J=11.1 \mathrm{~Hz}, 1 \mathrm{H}), 4.18(\mathrm{br} \mathrm{d}, J=12.5 \mathrm{~Hz}, 2 \mathrm{H}), 2.97-2.88(\mathrm{~m}, 2 \mathrm{H}), 2.67(\mathrm{q}, J=7.5 \mathrm{~Hz}, 2 \mathrm{H})$, $2.21-2.06(\mathrm{~m}, 5 \mathrm{H}), 1.98(\mathrm{br} \mathrm{d}, J=10.8 \mathrm{~Hz}, 2 \mathrm{H}), 1.28(\mathrm{~s}, 9 \mathrm{H}), 1.12(\mathrm{t}, J=7.4 \mathrm{~Hz}, 3 \mathrm{H})$ Preparation of Compound 6 :
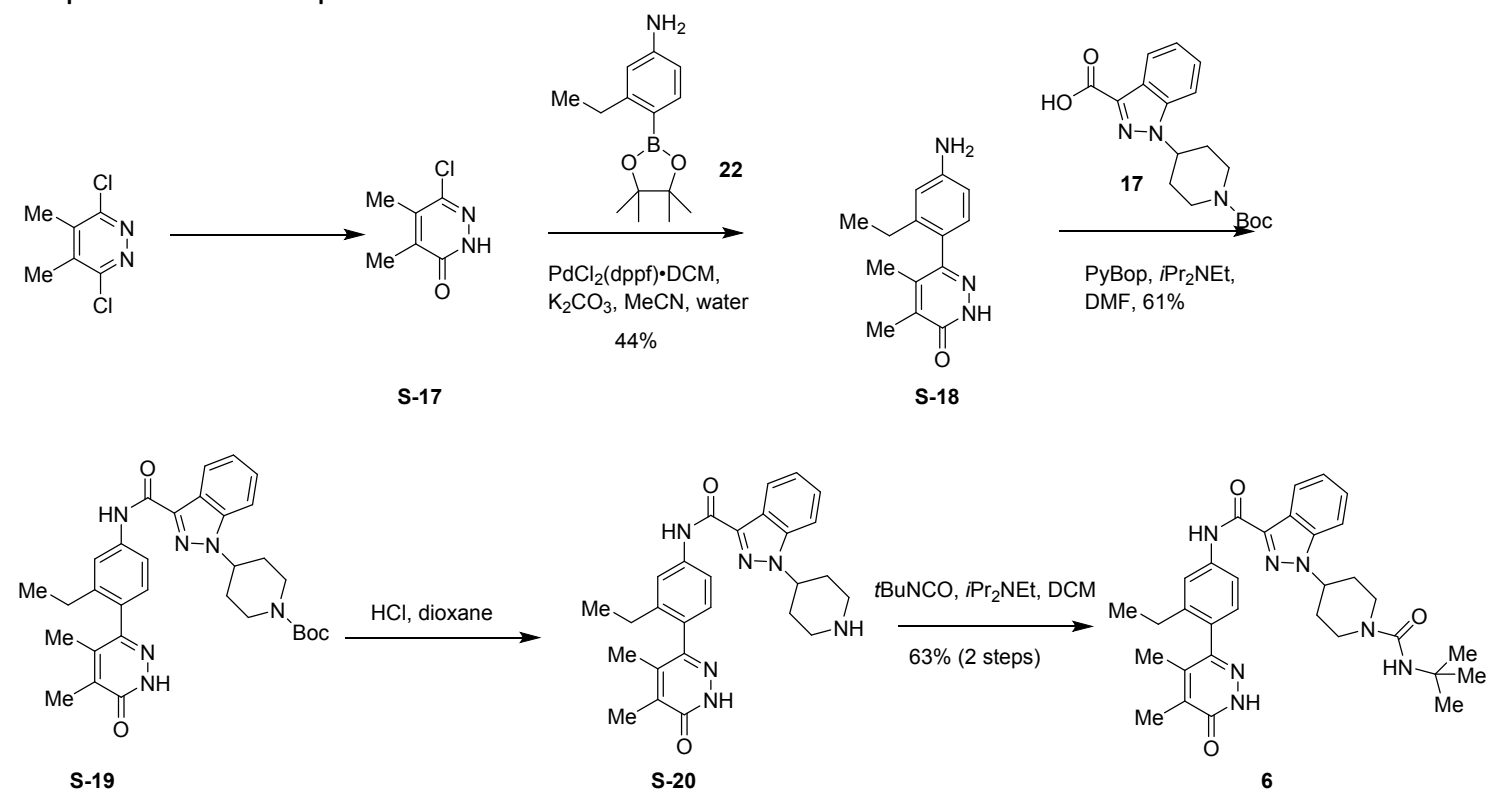

Preparation of 6-chloro-4,5-dimethylpyridazin-3(2H)-one (S-17):

3,6-dichloro-4,5-dimethylpyridazine $(1.0 \mathrm{~g}, 5.65 \mathrm{mmol})$ was dissolved in acetic acid $(22.59 \mathrm{ml})$ and heated to $110^{\circ} \mathrm{C}$ overnight. The reaction was concentrated, then carefully neutralized with sat. $\mathrm{NaHCO} 3$ solution and dried under vacuum to give 6-chloro-4,5-dimethylpyridazin-3(2H)-one (S-17) (0.448 g, 2.82 $\mathrm{mmol}, 50.0 \%$ yield), which was used without purification. LC/MS RT: $0.57 \mathrm{~min}$ (Method A). M/Z=159.1. Preparation of 6-(4-amino-2-ethylphenyl)-4,5-dimethylpyridazin-3(2H)-one (S-18):

3-ethyl-4-(4,4,5,5-tetramethyl-1,3,2-dioxaborolan-2-yl)aniline (0.203 g, $0.820 \mathrm{mmol}), 6$-chloro-4,5dimethylpyridazin-3(2H)-one (S-17) $(0.100 \mathrm{~g}, 0.631 \mathrm{mmol}), \mathrm{PdCl}_{2}(\mathrm{dppf})$-DCM adduct ( $0.051 \mathrm{~g}, 0.063$ $\mathrm{mmol})$, and potassium carbonate $(0.200 \mathrm{~g}, 1.450 \mathrm{mmol})$ were placed in a pressure vial. The vial was placed under vacuum and backfilled with nitrogen. Acetonitrile $(2.52 \mathrm{ml})$ and water $(1.682 \mathrm{ml})$ were added, then the reaction was heated at $100{ }^{\circ} \mathrm{C}$ for 7 hours. The reaction was cooled and extracted 
three times with EtOAc. The organic layers were dried with sodium sulfate and concentrated. The residue was purified via ISCO ( $24 \mathrm{~g}$ column; DCM/EtOAc; 0 to $100 \%$ gradient ;) to give 6 -(4-amino-2ethylphenyl)-4,5-dimethylpyridazin-3(2H)-one (S-18) $(0.067 \mathrm{~g}, 0.275 \mathrm{mmol}, 43.7 \%$ yield). LC/MS RT: $0.49 \min ($ Method $\mathrm{A}) . \mathrm{M} / \mathrm{Z}=244.2$.

Preparation of tert-butyl 4-(3-((4-(4,5-dimethyl-6-oxo-1,6-dihydropyridazin-3-yl)-3ethylphenyl)carbamoyl)-1H-indazol-1-yl)piperidine-1-carboxylate (S-19):

To a solution of 1-(1-(tert-butoxycarbonyl)piperidin-4-yl)-1H-indazole-3-carboxylic acid (17) $(0.124 \mathrm{~g}$, $0.358 \mathrm{mmol}$ ) and 6-(4-amino-2-ethylphenyl)-4,5-dimethylpyridazin-3(2H)-one (S-18) (0.067 g, 0.275 $\mathrm{mmol})$ in DMF (1.836 ml) was added Hunig's Base $(0.192 \mathrm{ml}, 1.102 \mathrm{mmol})$ and PyBOP $(0.186 \mathrm{~g}, 0.358$ $\mathrm{mmol})$. The reaction was stirred overnight, then diluted with water and extracted three times with EtOAc. The organic layers were washed with $10 \% \mathrm{LiCl}$ solution, dried with sodium sulfate, and concentrated. The residue was purified via ISCO ( $24 \mathrm{~g}$ column; Hex/EtOAc; 0 to $100 \%$ gradient) to give tert-butyl 4-(3-((4-(4,5-dimethyl-6-oxo-1,6-dihydropyridazin-3-yl)-3-ethylphenyl)carbamoyl)-1H-indazol1-yl)piperidine-1-carboxylate (S-19) $\left(0.096 \mathrm{~g}, 0.168 \mathrm{mmol}, 61.1 \%\right.$ yield). ${ }^{1} \mathrm{H} \mathrm{NMR}(400 \mathrm{MHz}$, CHLOROFORM-d) $\delta 12.12(\mathrm{~s}, 1 \mathrm{H}), 8.92(\mathrm{~s}, 1 \mathrm{H}), 8.47(\mathrm{~d}, \mathrm{~J}=8.2 \mathrm{~Hz}, 1 \mathrm{H}), 7.79-7.66(\mathrm{~m}, 2 \mathrm{H}), 7.55$ - $7.50(\mathrm{~m}$, $1 \mathrm{H}), 7.46(\mathrm{td}, J=7.6,0.9 \mathrm{~Hz}, 1 \mathrm{H}), 7.34(\mathrm{t}, J=7.5 \mathrm{~Hz}, 1 \mathrm{H}), 7.16(\mathrm{~d}, J=8.2 \mathrm{~Hz}, 1 \mathrm{H}), 4.67(\mathrm{tt}, J=11.3,4.0 \mathrm{~Hz}, 1 \mathrm{H})$, 4.37 (br s, 2H), 3.02 (br t, J=12.2 Hz, 2H), $2.62-2.27(\mathrm{~m}, 4 \mathrm{H}), 2.24(\mathrm{~s}, 3 \mathrm{H}), 2.10(\mathrm{br} \mathrm{d}, J=11.0 \mathrm{~Hz}, 2 \mathrm{H}), 1.96$ $(\mathrm{s}, 3 \mathrm{H}), 1.53(\mathrm{~s}, 9 \mathrm{H}), 1.17(\mathrm{t}, J=7.6 \mathrm{~Hz}, 3 \mathrm{H})$

Preparation of N-(4-(4,5-dimethyl-6-oxo-1,6-dihydropyridazin-3-yl)-3-ethylphenyl)-1-(piperidin-4-yl)-1Hindazole-3-carboxamide, $2 \mathrm{HCl}$ (S-20):

tert-butyl 4-(3-((4-(4,5-dimethyl-6-oxo-1,6-dihydropyridazin-3-yl)-3-ethylphenyl)carbamoyl)-1H-indazol1-yl)piperidine-1-carboxylate (S-19) $(0.096 \mathrm{~g}, 0.168 \mathrm{mmol})$ was suspended in $4 \mathrm{M} \mathrm{HCl}$ in dioxane $(3 \mathrm{~mL})$. After 45 minutes, the reaction was concentrated and azeotroped with hexanes to give $\mathrm{N}-(4-(4,5-$ dimethyl-6-oxo-1,6-dihydropyridazin-3-yl)-3-ethylphenyl)-1-(piperidin-4-yl)-1H-indazole-3-carboxamide, $2 \mathrm{HCl},(\mathbf{S}-20)$ (142 mg, >100\% yield) which was used directly in subsequent reactions. LC/MS RT: 0.69 $\min ($ Method $A) . M / Z=471.2$.

Preparation of 1-(1-(tert-butylcarbamoyl)piperidin-4-yl)-N-(4-(4,5-dimethyl-6-oxo-1,6-dihydropyridazin3-yl)-3-ethylphenyl)-1H-indazole-3-carboxamide (6):

To a suspension of $\mathrm{N}$-(4-(4,5-dimethyl-6-oxo-1,6-dihydropyridazin-3-yl)-3-ethylphenyl)-1-(piperidin-4-yl)$1 \mathrm{H}$-indazole-3-carboxamide, $2 \mathrm{HCl}(\mathbf{S}-20)(0.071 \mathrm{~g}, 0.131 \mathrm{mmol})$ in DCM $(1.5 \mathrm{~mL})$ was added Hunig's Base $(0.091 \mathrm{~mL}, 0.523 \mathrm{mmol})$ and $t$-butyl isocyanate $(0.019 \mathrm{~mL}, 0.170 \mathrm{mmol})$. After 1.75 hours, the reaction was quenched with $\mathrm{MeOH}$ and concentrated, then azeotroped twice with $\mathrm{MeOH}$. The solid was triturated with $\mathrm{MeOH}$, filtered, and dried to give 1-(1-(tert-butylcarbamoyl)piperidin-4-yl)-N-(4-(4,5dimethyl-6-oxo-1,6-dihydropyridazin-3-yl)-3-ethylphenyl)-1H-indazole-3-carboxamide (6) (0.047 g, 0.082 mmol, $63.2 \%$ yield from S-19).

HPLC RT: 9.58 min (Method B). Purity 100\%. M/Z=570.4. ${ }^{1} \mathrm{H} N M R\left(400 \mathrm{MHz}, \mathrm{DMSO}-\mathrm{d}_{6}\right) \delta 12.88(\mathrm{~s}, 1 \mathrm{H})$, $10.13(\mathrm{~s}, 1 \mathrm{H}), 8.24(\mathrm{~d}, J=8.1 \mathrm{~Hz}, 1 \mathrm{H}), 7.90(\mathrm{~d}, J=8.8 \mathrm{~Hz}, 1 \mathrm{H}), 7.85-7.78(\mathrm{~m}, 2 \mathrm{H}), 7.50(\mathrm{t}, J=7.3 \mathrm{~Hz}, 1 \mathrm{H}), 7.33$ (t, J=7.4 Hz, 1H), 7.15 (d, J=8.6 Hz, 1H), $5.87(\mathrm{~s}, 1 \mathrm{H}), 4.96(\mathrm{br} \mathrm{t}, J=11.0 \mathrm{~Hz}, 1 \mathrm{H}), 4.20(\mathrm{br} \mathrm{d}, J=13.4 \mathrm{~Hz}, 2 \mathrm{H})$, 2.98 - $2.84(\mathrm{~m}, 2 \mathrm{H}), 2.46-2.42(\mathrm{~m}, 2 \mathrm{H})$ (ovelaps DMSO), $2.21-2.11(\mathrm{~m}, 2 \mathrm{H}), 2.08(\mathrm{~s}, 3 \mathrm{H}), 1.99$ (br d, J=9.2 $\mathrm{Hz}, 2 \mathrm{H}), 1.87(\mathrm{~s}, 3 \mathrm{H}), 1.29(\mathrm{~s}, 9 \mathrm{H}), 1.07$ (t, J=7.6 Hz, 3H)

Preparation of compound 7: 


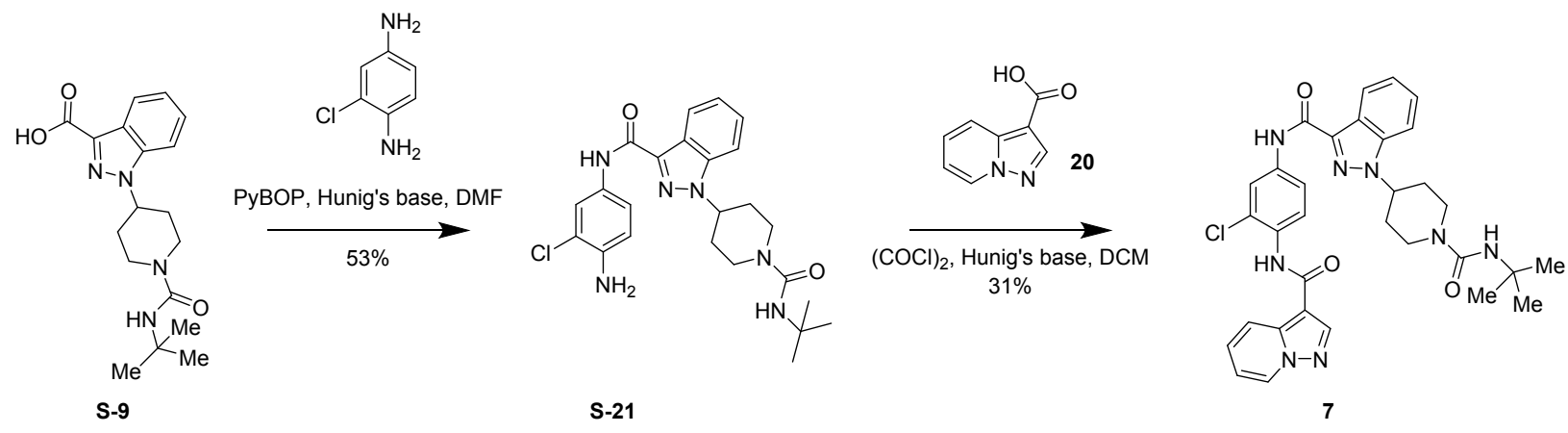

Preparation of N-(4-amino-3-chlorophenyl)-1-(1-(tert-butylcarbamoyl)piperidin-4-yl)-1H-indazole-3carboxamide (S-21):

To a suspension of 2-chlorobenzene-1,4-diamine, sulfuric acid salt (30 mg, $0.125 \mathrm{mmol}$ ) and 1-(1-(tertbutylcarbamoyl)piperidin-4-yl)-1H-indazole-3-carboxylic acid (S-9) $(51.5 \mathrm{mg}, 0.150 \mathrm{mmol}$ ) in DMF (831 $\mu \mathrm{l})$ was added PyBOP $(97 \mathrm{mg}, 0.187 \mathrm{mmol})$ and Hunig'sBase $(87 \mu \mathrm{l}, 0.499 \mathrm{mmol})$. The mixture was stirred at $\mathrm{rt}$ for 16 hours. The solvent was evaporated and the residue was purified by ISCO $12 \mathrm{~g}$ column, $0 \rightarrow 100 \%$ EtOAc in Hexanes) to afford N-(4-amino-3-chlorophenyl)-1-(1-(tertbutylcarbamoyl)piperidin-4-yl)-1H-indazole-3-carboxamide (S-21) (31 mg, $0.066 \mathrm{mmol}, 53.0 \%$ yield). LC/MS RT: 0.93 min (Method A). M/Z= 469.3.

Preparation of 1-(1-(tert-butylcarbamoyl)piperidin-4-yl)-N-(3-chloro-4-(pyrazolo[1,5-a]pyridine-3carboxamido)phenyl)-1H-indazole-3-carboxamide (7):

To a suspension of pyrazolo[1,5-a]pyridine-3-carboxylic acid (S-21) $(5.19 \mathrm{mg}, 0.032 \mathrm{mmol})$ in DCM (350 $\mu \mathrm{l})$, oxalyl chloride $(5.60 \mu \mathrm{l}, 0.064 \mathrm{mmol})$ was added. The reaction was stirred at $\mathrm{rt}$ for 1 hour. The solvent was evaporated and the residue was dried in vacuo. The residue was then dissolved in DCM (350 $\mu \mathrm{l})$ followed by addition of $\mathrm{N}$-(4-amino-3-chlorophenyl)-1-(1-(tert-butylcarbamoyl)piperidin-4-yl)-1Hindazole-3-carboxamide $(15 \mathrm{mg}, 0.032 \mathrm{mmol})$ and Hunig'sBase $(27.9 \mu \mathrm{l}, 0.160 \mathrm{mmol})$. The reaction was for 16 hours, then quenched with $\mathrm{MeOH}$. The solvent was evaporated and the residue was purified by reverse phase HPLC (Water:MeOH) to afford 1-(1-(tert-butylcarbamoyl)piperidin-4-yl)-N-(3-chloro-4(pyrazolo[1,5-a]pyridine-3-carboxamido)phenyl)-1H-indazole-3-carboxamide (7) $(6 \mathrm{mg}, 9.79 \mu \mathrm{mol}, 31 \%$ yield).

HPLC RT: $23.53 \mathrm{~min}$ (Method A). Purity $96.8 \% . \mathrm{M} / \mathrm{Z}=613.3 .{ }^{1} \mathrm{H}$ NMR (400 MHz, CHLOROFORM-d) $\delta 8.87$ $(\mathrm{s}, 1 \mathrm{H}), 8.66-8.60(\mathrm{~m}, 1 \mathrm{H}), 8.51(\mathrm{~d}, J=8.9 \mathrm{~Hz}, 1 \mathrm{H}), 8.47-8.43(\mathrm{~m}, 1 \mathrm{H}), 8.40(\mathrm{dt}, J=8.9,1.1 \mathrm{~Hz}, 1 \mathrm{H}), 8.36(\mathrm{~s}$, $1 \mathrm{H}), 8.23(\mathrm{~d}, \mathrm{~J}=2.3 \mathrm{~Hz}, 1 \mathrm{H}), 8.15(\mathrm{~s}, 1 \mathrm{H}), 7.55-7.45(\mathrm{~m}, 4 \mathrm{H}), 7.39-7.33(\mathrm{~m}, 1 \mathrm{H}), 7.05(\mathrm{td}, \mathrm{J}=6.9,1.3 \mathrm{~Hz}$, $1 \mathrm{H}), 4.75-4.65(\mathrm{~m}, 1 \mathrm{H}), 4.20-4.07(\mathrm{~m}, 2 \mathrm{H}), 3.19-3.04(\mathrm{~m}, 2 \mathrm{H}), 2.45-2.30(\mathrm{~m}, 2 \mathrm{H}), 2.16(\mathrm{br} \mathrm{dd}, J=12.7$, $2.3 \mathrm{~Hz}, 2 \mathrm{H}), 1.42(\mathrm{~s}, 9 \mathrm{H})$

Preparation of compound 8: 


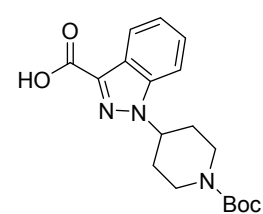

17

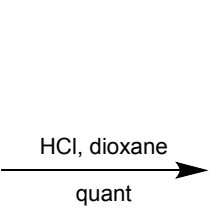

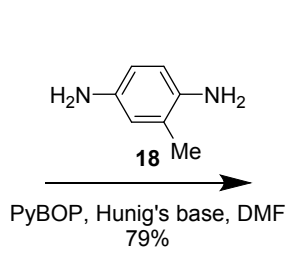

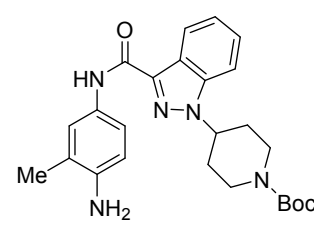

19

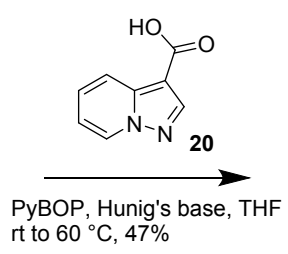

rt to $60{ }^{\circ} \mathrm{C}, 47 \%$
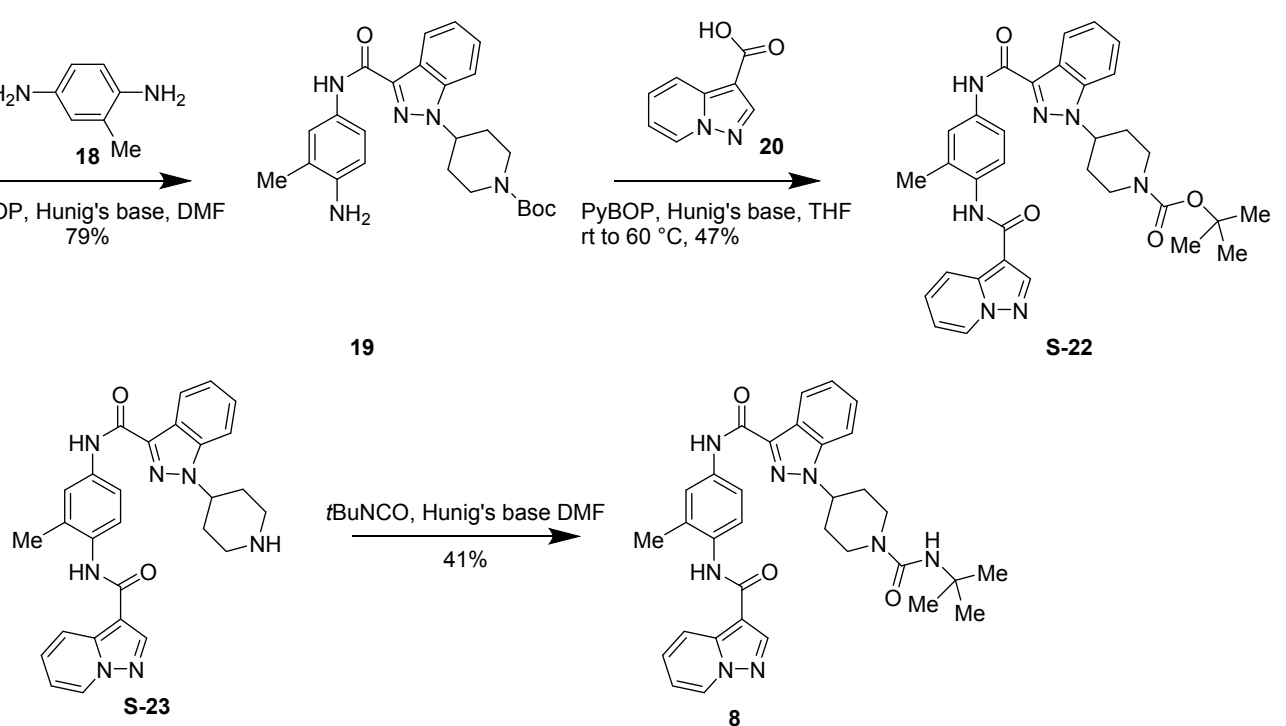

Preparation of tert-butyl 4-(3-((4-amino-3-methylphenyl)carbamoyl)-1H-indazol-1-yl)piperidine-1carboxylate (19):

1-(1-(tert-butoxycarbonyl)piperidin-4-yl)-1H-indazole-3-carboxylic acid (17) (0.130 g, $0.376 \mathrm{mmol}$ ) and 2methylbenzene-1,4-diamine, sulfuric acid salt $(0.166 \mathrm{~g}, 0.753 \mathrm{mmol})$ were suspended in DMF (1.882 $\mathrm{ml})$. Hunig'sBase $(0.197 \mathrm{ml}, 1.129 \mathrm{mmol})$ and PyBOP $(0.274 \mathrm{~g}, 0.527 \mathrm{mmol})$ were added, and the reaction was stirred overnight. The reaction was diluted with water and extracted three times with EtOAc. The organic layers were washed with $10 \% \mathrm{LiCl}$ solution, dried with sodium sulfate, and concentrated. The residue was purified via ISCO ( $24 \mathrm{~g}$ column; DCM/MeOH; 0 to $7 \%$ gradient0 to give tert-butyl 4-(3-((4amino-3-methylphenyl)carbamoyl)-1H-indazol-1-yl)piperidine-1-carboxylate (19) $(0.133 \mathrm{~g}, 0.296 \mathrm{mmol}$, $79 \%$ yield). ${ }^{1} \mathrm{H}$ NMR (400 MHz, CHLOROFORM-d) $\delta 8.66(\mathrm{~s}, 1 \mathrm{H}), 8.47$ (d, J=8.2 Hz, 1H), 7.52 - 7.48 (m, $2 \mathrm{H}), 7.46-7.37(\mathrm{~m}, 2 \mathrm{H}), 7.34-7.28(\mathrm{~m}, 1 \mathrm{H}), 6.70(\mathrm{~d}, \mathrm{~J}=8.3 \mathrm{~Hz}, 1 \mathrm{H}), 4.68$ - $4.58(\mathrm{~m}, 1 \mathrm{H}), 4.36(\mathrm{br} \mathrm{s}, 2 \mathrm{H})$, $3.58(\mathrm{br} \mathrm{s}, 2 \mathrm{H}), 3.10-2.91(\mathrm{~m}, 2 \mathrm{H}), 2.36-2.24(\mathrm{~m}, 2 \mathrm{H}), 2.23-2.16(\mathrm{~m}, 3 \mathrm{H}), 2.12-2.04(\mathrm{~m}, 2 \mathrm{H}), 1.53(\mathrm{~s}$, $9 \mathrm{H})$. The regiochemistry of the acylation was confirmed by observation of NOEs from the amide NH to the adjacent aryl protons.

Preparation of tert-butyl 4-(3-((3-methyl-4-(pyrazolo[1,5-a]pyridine-3-carboxamido)phenyl)carbamoyl)$1 \mathrm{H}$-indazol-1-yl)piperidine-1-carboxylate (S-22):

To a suspension of pyrazolo[1,5-a]pyridine-3-carboxylic acid $(0.053 \mathrm{~g}, 0.327 \mathrm{mmol})$ and tert-butyl 4-(3((4-amino-3-methylphenyl)carbamoyl)-1H-indazol-1-yl)piperidine-1-carboxylate (19) (0.105 g, 0.234 $\mathrm{mmol})$ in THF $(1.557 \mathrm{ml})$ was added Hunig'sBase $(0.122 \mathrm{ml}, 0.701 \mathrm{mmol})$ and PyBOP $(0.194 \mathrm{~g}, 0.374$ $\mathrm{mmol}$ ). The reaction was stirred overnight, then heated to $60^{\circ} \mathrm{C}$ for 8 hours. The reaction was cooled, diluted with water, and extracted twice with EtOAc. The organic layers were dried with sodium sulfate and concentrated. The residue was purified via ISCO ( $24 \mathrm{~g}$ column; Hex/EtOAc; 0 to $100 \%$ gradient;) to give tert-butyl 4-(3-((3-methyl-4-(pyrazolo[1,5-a]pyridine-3-carboxamido)phenyl)carbamoyl)-1H-indazol1-yl)piperidine-1-carboxylate (S-22) $(0.065 \mathrm{~g}, 0.109 \mathrm{mmol}, 46.9 \%$ yield). LC/MS RT: $1.03 \mathrm{~min}$ (Method A). $M / Z=594.5$.

Preparation of N-(3-methyl-4-(pyrazolo[1,5-a]pyridine-3-carboxamido)phenyl)-1-(piperidin-4-yl)-1Hindazole-3-carboxamide, $2 \mathrm{HCl}$ (S-23):

tert-butyl 4-(3-((3-methyl-4-(pyrazolo[1,5-a]pyridine-3-carboxamido)phenyl)carbamoyl)-1H-indazol-1yl)piperidine-1-carboxylate (S-22) $(0.065 \mathrm{~g}, 0.109 \mathrm{mmol})$ was suspended in $4 \mathrm{M} \mathrm{HCl}$ in dioxane $(2 \mathrm{~mL})$. After ca 2 hours, the reaction was concentrated to give $\mathrm{N}$-(3-methyl-4-(pyrazolo[1,5-a]pyridine-3carboxamido)phenyl)-1-(piperidin-4-yl)-1H-indazole-3-carboxamide, $2 \mathrm{HCl}$ (S-23) $(0.066 \mathrm{~g}, 0.117 \mathrm{mmol}$, $106 \%$ yield). LC/MS RT: 0.70 min (Method $A$ ). M/Z= 494.1. 
Preparation of 1-(1-(tert-butylcarbamoyl)piperidin-4-yl)-N-(3-methyl-4-(pyrazolo[1,5-a]pyridine-3carboxamido)phenyl)-1H-indazole-3-carboxamide (8):

To a solution of $\mathrm{N}$-(3-methyl-4-(pyrazolo[1,5-a]pyridine-3-carboxamido)phenyl)-1-(piperidin-4-yl)-1Hindazole-3-carboxamide, $2 \mathrm{HCl}(\mathbf{S}-23)(0.024 \mathrm{~g}, 0.042 \mathrm{mmol})$ in DMF $(0.4 \mathrm{~mL})$ was added Hunig'sBase $(0.030 \mathrm{~mL}, 0.169 \mathrm{mmol})$ and tbutyl isocyanate $(6.29 \mu \mathrm{l}, 0.055 \mathrm{mmol})$. The reaction was stirred overnight.The crude material was purified via preparative HPLC with the following conditions: Column: Luna C18, $30 \times 100 \mathrm{~mm}, 5-\mu \mathrm{m}$ particles; Mobile Phase A: 10:90 MeOH: water with 0.1\%TFA; Mobile Phase B: 90:10 MeOH: water with 100.1\%TFA; Gradient:0-100\% B over 12 minutes, then a 4-minute hold at $100 \%$ B; Flow: $25 \mathrm{~mL} / \mathrm{min}$. The material was purified a second time via preparative LC/MS with the following conditions: Column: XBridge Shield RP18, $19 \times 200$ mm, 5- $\mu \mathrm{m}$ particles; Mobile Phase A: 5:95 acetonitrile: water with 10-mM ammonium acetate; Mobile Phase B: 95:5 acetonitrile: water with 10mM ammonium acetate; Gradient: $20-60 \%$ B over 25 minutes, then a 5-minute hold at $100 \%$ B; Flow: 20 $\mathrm{mL} / \mathrm{min}$ to give 1-(1-(tert-butylcarbamoyl)piperidin-4-yl)-N-(3-methyl-4-(pyrazolo[1,5-a]pyridine-3carboxamido)phenyl)-1H-indazole-3-carboxamide (8) (10.4 mg, 41\%).

LCMS RT: 1.82 min (Method B). Purity 98.8\%. M/Z=593.1. ${ }^{1} \mathrm{H}$ NMR (500 MHz, DMSO-d 6 ) $\delta 10.06$ (s, $1 \mathrm{H}), 9.61(\mathrm{~s}, 1 \mathrm{H}), 8.82(\mathrm{~d}, J=6.9 \mathrm{~Hz}, 1 \mathrm{H}), 8.74(\mathrm{br} \mathrm{s}, 1 \mathrm{H}), 8.23(\mathrm{br} \mathrm{d}, J=8.2 \mathrm{~Hz}, 2 \mathrm{H}), 7.89(\mathrm{~d}, J=8.7 \mathrm{~Hz}, 1 \mathrm{H})$, $7.78(\mathrm{~s}, 1 \mathrm{H}), 7.75-7.69(\mathrm{~m}, 1 \mathrm{H}), 7.54-7.46(\mathrm{~m}, 2 \mathrm{H}), 7.38-7.29(\mathrm{~m}, 2 \mathrm{H}), 7.10(\mathrm{t}, \mathrm{J}=6.6 \mathrm{~Hz}, 1 \mathrm{H}), 5.89(\mathrm{~s}$, $1 \mathrm{H}), 5.03-4.88(\mathrm{~m}, 1 \mathrm{H}), 4.19(\mathrm{br} \mathrm{d}, J=12.9 \mathrm{~Hz}, 2 \mathrm{H}), 2.94-2.87(\mathrm{~m}, 2 \mathrm{H}), 2.27(\mathrm{~s}, 3 \mathrm{H}), 2.20-2.08(\mathrm{~m}, 2 \mathrm{H})$, 1.98 (br d, J=10.5 Hz, 2H), $1.29(\mathrm{~s}, 9 \mathrm{H}$ )

Preparation of compound 9:

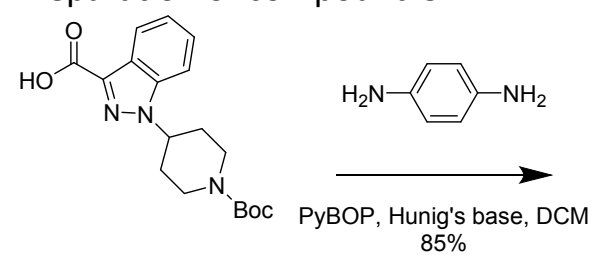

$85 \%$

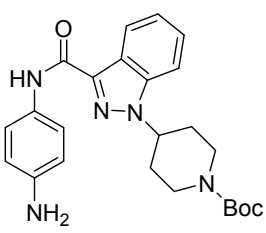

S-24

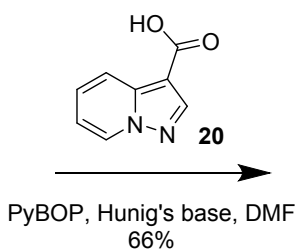

$66 \%$
17

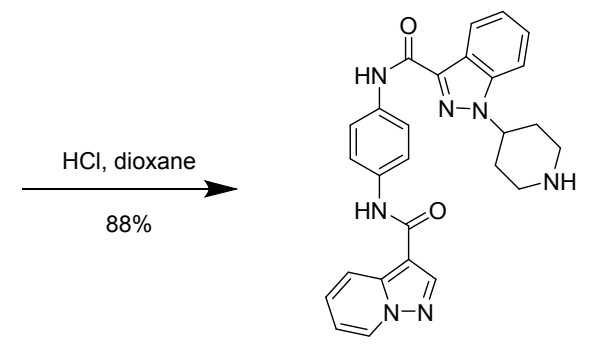

S-26

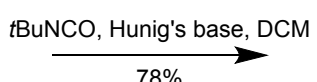

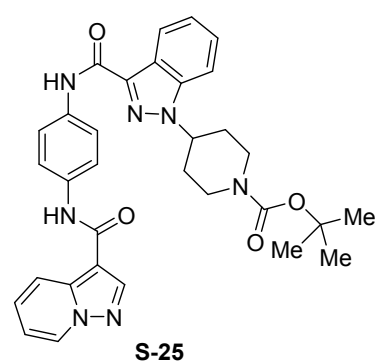

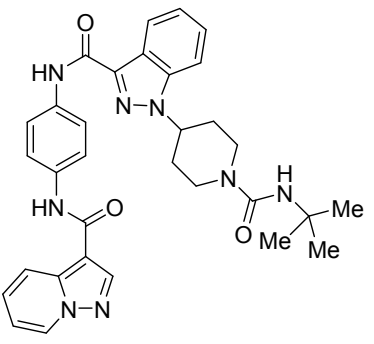

9

Preparation of tert-butyl 4-(3-((4-aminophenyl)carbamoyl)-1H-indazol-1-yl)piperidine-1-carboxylate (S-

24):

To a suspension of benzene-1,4-diamine $(50 \mathrm{mg}, 0.462 \mathrm{mmol}$ ) and 1-(1-(tert-butoxycarbonyl)piperidin-4yl)-1H-indazole-3-carboxylic acid (17) $(160 \mathrm{mg}, 0.462 \mathrm{mmol})$ in DCM (1541 $\mu \mathrm{l})$ was added PyBOP (241 $\mathrm{mg}, 0.462 \mathrm{mmol}$ ) and Hunig'sBase $(250 \mu \mathrm{l}, 1.433 \mathrm{mmol})$. The mixture was stirred at $\mathrm{rt}$ for 72 hours. The reaction was quenched with $\mathrm{MeOH}$, concentrated and purified by ISCO ( $24 \mathrm{~g}$ column, $0 \rightarrow 100 \%$ EtOAc in Hexanes) to afford tert-butyl 4-(3-((4-aminophenyl)carbamoyl)-1H-indazol-1-yl)piperidine-1-carboxylate (S-24) (172 mg, $0.395 \mathrm{mmol}, 85 \%$ yield). LC/MS RT: $0.86 \mathrm{~min}$ (Method A). M/Z= 436.4.

Preparation of ( tert-butyl 4-(3-((4-(pyrazolo[1,5-a]pyridine-3-carboxamido)phenyl)carbamoyl)-1Hindazol-1-yl)piperidine-1-carboxylate (S-25): 
To a suspension of tert-butyl 4-(3-((4-aminophenyl)carbamoyl)-1H-indazol-1-yl)piperidine-1-carboxylate (100 mg, $0.230 \mathrm{mmol})(\mathbf{S}-24)$ and pyrazolo[1,5-a]pyridine-3-carboxylic acid (17) $(41.0 \mathrm{mg}, 0.253 \mathrm{mmol})$ in DMF (1531 $\mu \mathrm{l})$ was added PyBOP (143 mg, $0.276 \mathrm{mmol})$ and Hunig'sBase $(160 \mu \mathrm{l}, 0.918 \mathrm{mmol})$. The mixture was stirred at rt for 12 hours. The reaction was diluted with water and extracted twice with EtOAc. The organic layer was washed with $10 \% \mathrm{LiCl}$ solution, dried with sodium sulfate, and concentrated. The residue was purified via ISCO ( $24 \mathrm{~g}$ column; Hex/EtOAc; 0 to $100 \%$ gradient) to give tert-butyl 4-(3-((4-(pyrazolo[1,5-a]pyridine-3-carboxamido)phenyl)carbamoyl)-1H-indazol-1yl)piperidine-1-carboxylate (S-25) (88 mg, $0.152 \mathrm{mmol}, 66.1 \%$ yield). LC/MS RT: $1.11 \mathrm{~min}$ (Method A). $\mathrm{M} / \mathrm{Z}=580.3$.

Preparation of (1-(piperidin-4-yl)-N-(4-(pyrazolo[1,5-a]pyridine-3-carboxamido)phenyl)-1H-indazole-3carboxamide, $2 \mathrm{HCl}(\mathrm{S}-26)$ :

$\mathrm{HCl}$ (4M in Dioxane) $(1139 \mu \mathrm{l}, 4.55 \mathrm{mmol})$ was added to tert-butyl 4-(3-((4-(pyrazolo[1,5-a]pyridine-3carboxamido)phenyl)carbamoyl)-1H-indazol-1-yl)piperidine-1-carboxylate (S-25) $(88 \mathrm{mg}, 0.152 \mathrm{mmol})$ in a vial. The reaction was stirred at $r$ for 3 hours. The reaction was concentrated, triturated with ether and filtered to give 1-(piperidin-4-yl)- $\mathrm{N}$-(4-(pyrazolo[1,5-a]pyridine-3-carboxamido)phenyl)-1H-indazole3-carboxamide, $2 \mathrm{HCl}$ (S-26) (74 $\mathrm{mg}, 0.134 \mathrm{mmol}, 88 \%$ yield). Used as is for the next step. LC/MS RT: $0.80 \mathrm{~min}$ (Method $\mathrm{A}) . \mathrm{M} / \mathrm{Z}=480.3$.

Preparation of 1-(1-(tert-butylcarbamoyl)piperidin-4-yl)-N-(4-(pyrazolo[1,5-a]pyridine-3carboxamido)phenyl)-1H-indazole-3-carboxamide (9):

To a suspension of 1-(piperidin-4-yl)-N-(4-(pyrazolo[1,5-a]pyridine-3-carboxamido)phenyl)-1H-indazole3-carboxamide, $2 \mathrm{HCl}(\mathbf{S}-26)(15 \mathrm{mg}, 0.027 \mathrm{mmol})$ in DCM $(0.300 \mathrm{~mL})$ was added Hunig'sBase $(0.028 \mathrm{~mL}$, $0.163 \mathrm{mmol})$ and 2-isocyanato-2-methylpropane $(4.65 \mu \mathrm{l}, 0.041 \mathrm{mmol})$. The reaction was stirred at $\mathrm{rt}$ for 3 hours. The solvent was evaporated and the residue was dissolved in $\mathrm{MeOH}$ and the crude material was purified via preparative LC/MS with the following conditions: Column: XBridge C18, $19 \times 200 \mathrm{~mm}$, 5$\mu \mathrm{m}$ particles; Mobile Phase A: 5:95 acetonitrile: water with 10-mM ammonium acetate; Mobile Phase B: 95:5 acetonitrile: water with 10-mM ammonium acetate; Gradient: 20-80\% B over 20 minutes, then a 5minute hold at $100 \% \mathrm{~B}$; Flow: $20 \mathrm{~mL} / \mathrm{min}$. Fractions containing the desired product were combined and dried via centrifugal evaporation to give 1-(1-(tert-butylcarbamoyl)piperidin-4-yl)-N-(4-(pyrazolo[1,5a]pyridine-3-carboxamido)phenyl)-1H-indazole-3-carboxamide (9) (12.2 mg, 78\%). LCMS RT: $1.82 \mathrm{~min}$ (Method B). Purity 100\%. M/Z= 579.2. ${ }^{1} \mathrm{H} N M R\left(500 \mathrm{MHz}, \mathrm{DMSO}-\mathrm{d}_{6}\right)$ ? $10.09(\mathrm{~s}, 1 \mathrm{H}), 10.00(\mathrm{~s}, 1 \mathrm{H})$, $8.83(\mathrm{~d}, J=6.9 \mathrm{~Hz}, 1 \mathrm{H}), 8.80(\mathrm{~s}, 1 \mathrm{H}), 8.29(\mathrm{~d}, J=8.8 \mathrm{~Hz}, 1 \mathrm{H}), 8.24(\mathrm{~d}, J=8.2 \mathrm{~Hz}, 1 \mathrm{H}), 7.89(\mathrm{~d}, J=8.6 \mathrm{~Hz}, 1 \mathrm{H})$, $7.85-7.82(\mathrm{~m}, 2 \mathrm{H}), 7.75(\mathrm{~d}, J=8.9 \mathrm{~Hz}, 2 \mathrm{H}), 7.58-7.47(\mathrm{~m}, 2 \mathrm{H}), 7.34(\mathrm{t}, J=7.5 \mathrm{~Hz}, 1 \mathrm{H}), 7.13(\mathrm{t}, J=6.9 \mathrm{~Hz}, 1 \mathrm{H})$, $5.90(\mathrm{~s}, 1 \mathrm{H}), 4.96(\mathrm{t}, J=11.2 \mathrm{~Hz}, 1 \mathrm{H}), 4.20(\mathrm{~d}, J=13.0 \mathrm{~Hz}, 2 \mathrm{H}), 2.97-2.88(\mathrm{~m}, 2 \mathrm{H}), 2.21-2.09(\mathrm{~m}, 2 \mathrm{H}), 1.99$ (d, J=10.8 Hz, 2H), 1.30 (s, 9H).

Preparation of compound $\mathbf{1 0}$ : 


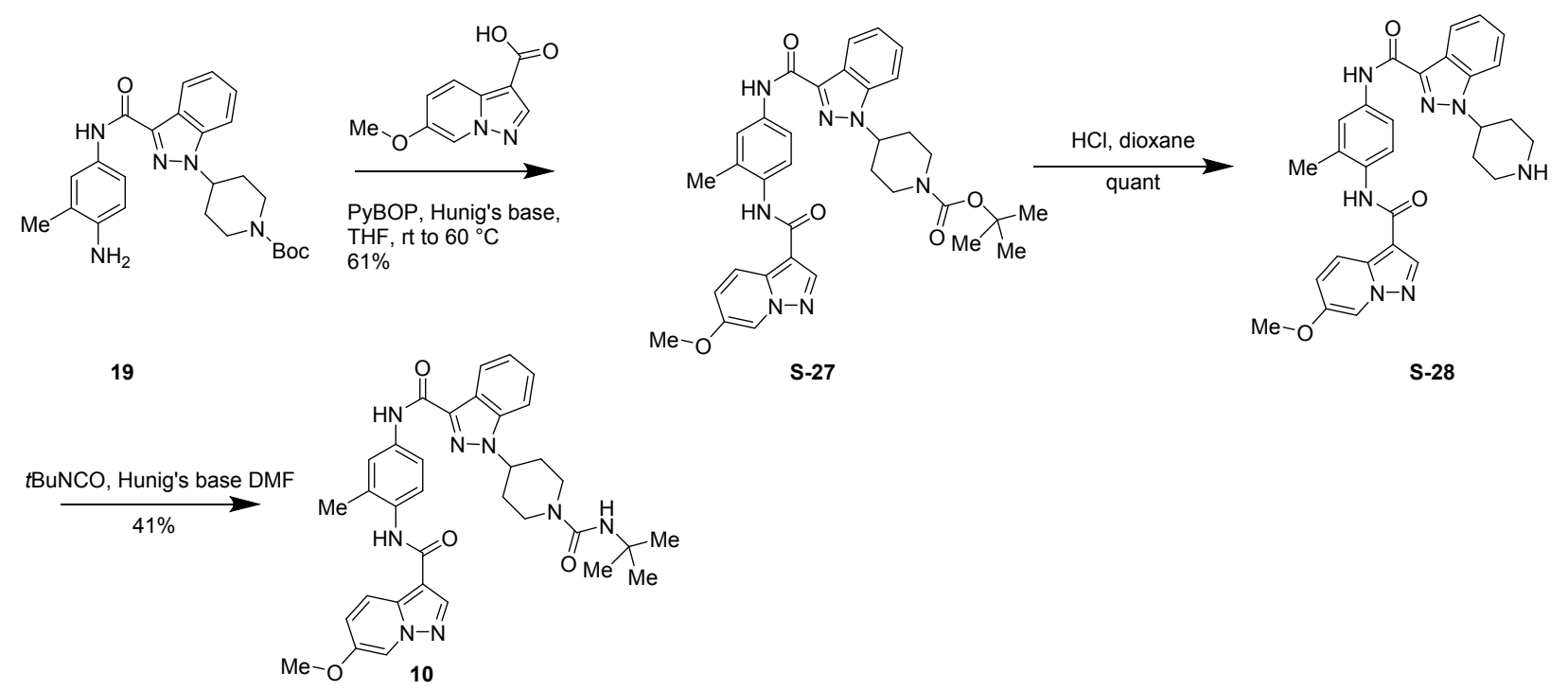

Preparation of tert-butyl 4-(3-((4-(6-methoxypyrazolo[1,5-a]pyridine-3-carboxamido)-3-

methylphenyl)carbamoyl)-1H-indazol-1-yl)piperidine-1-carboxylate (S-27):

To a suspension of 6-methoxypyrazolo[1,5-a]pyridine-3-carboxylic acid $(0.015 \mathrm{~g}, 0.078 \mathrm{mmol})$ and tertbutyl 4-(3-((4-amino-3-methylphenyl)carbamoyl)-1H-indazol-1-yl)piperidine-1-carboxylate (19) (0.025 g, $0.056 \mathrm{mmol})$ in THF $(0.371 \mathrm{ml})$ was added Hunig'sBase $(0.029 \mathrm{ml}, 0.167 \mathrm{mmol})$ and PyBOP $(0.046 \mathrm{~g}$, $0.089 \mathrm{mmol}$ ) and stirred overnight. The reaction was then heated to $60^{\circ} \mathrm{C}$ for 1 hour. The reaction was loaded directly onto an ISCO column. The residue was purified via ISCO ( $24 \mathrm{~g}$ column; Hex/EtOAc; 0 to $100 \%$ gradient) to give tert-butyl 4-(3-((4-(6-methoxypyrazolo[1,5-a]pyridine-3-carboxamido)-3methylphenyl)carbamoyl)-1H-indazol-1-yl)piperidine-1-carboxylate (S-27) $(0.021 \mathrm{~g}, 0.034 \mathrm{mmol}, 60.5 \%$ yield). LC/MS RT: $1.05 \mathrm{~min}$ (Method $A)$. M/Z=624.2.

Preparation of N-(4-(6-methoxypyrazolo[1,5-a]pyridine-3-carboxamido)-3-methylphenyl)-1-(piperidin-4yl)-1H-indazole-3-carboxamide, $2 \mathrm{HCl}(\mathbf{S}-28)$ :

tert-butyl 4-(3-((4-(6-methoxypyrazolo[1,5-a]pyridine-3-carboxamido)-3-methylphenyl)carbamoyl)-1Hindazol-1-yl)piperidine-1-carboxylate (S-27) $(0.020 \mathrm{~g}, 0.032 \mathrm{mmol})$ was suspended in $4 \mathrm{M} \mathrm{HCl}$ in dioxane $(1 \mathrm{~mL})$. After ca. 1 hour, the reaction was concentrated to give N-(4-(6-methoxypyrazolo[1,5-a]pyridine3-carboxamido)-3-methylphenyl)-1-(piperidin-4-yl)-1H-indazole-3-carboxamide, $2 \mathrm{HCl}$ (S-28) $(0.023 \mathrm{~g}$, $0.039 \mathrm{mmol}, 120 \%$ yield). LC/MS RT: $0.73 \mathrm{~min}$ (Method A). M/Z=524.5.

Preparation of 1-(1-(tert-butylcarbamoyl)piperidin-4-yl)-N-(4-(6-methoxypyrazolo[1,5-a]pyridine-3carboxamido)-3-methylphenyl)-1H-indazole-3-carboxamide (10):

To a solution of $\mathrm{N}$-(4-(6-methoxypyrazolo[1,5-a]pyridine-3-carboxamido)-3-methylphenyl)-1-(piperidin4-yl)-1H-indazole-3-carboxamide, $2 \mathrm{HCl}(\mathbf{S}-28)(0.023 \mathrm{~g}, 0.039 \mathrm{mmol})$ in DMF $(0.4 \mathrm{~mL})$ was added Hunig'sBase $(0.020 \mathrm{~mL}, 0.116 \mathrm{mmol})$ and tbutyl isocyanate $(6.61 \mu \mathrm{l}, 0.058 \mathrm{mmol})$. After 1.5 hours, the reaction was diluted with DMF, filtered through a syringe filter, and The crude material was purified via preparative LC/MS with the following conditions: Column: XBridge C18, $19 \times 200 \mathrm{~mm}, 5-\mu \mathrm{m}$ particles; Mobile Phase A: 5:95 acetonitrile: water with 10-mM ammonium acetate; Mobile Phase B: 95:5 acetonitrile: water with $10-\mathrm{mM}$ ammonium acetate; Gradient: $20-75 \%$ B over 20 minutes, then a 5minute hold at $100 \%$ B; Flow: $20 \mathrm{~mL} / \mathrm{min}$. Fractions containing the desired product were combined and dried via centrifugal evaporation to give 1-(1-(tert-butylcarbamoyl)piperidin-4-yl)-N-(4-(6methoxypyrazolo[1,5-a]pyridine-3-carboxamido)-3-methylphenyl)-1H-indazole-3-carboxamide (10) (10.4 $\mathrm{mg}, 41 \%)$. LCMS RT: $1.82 \mathrm{~min}$ (Method C). Purity 95\%. $\mathrm{M} / \mathrm{Z}=623.2 .{ }^{1} \mathrm{H}$ NMR $\left(500 \mathrm{MHz}, \mathrm{DMSO}-\mathrm{d}_{6}\right) \delta$ $10.06(\mathrm{~s}, 1 \mathrm{H}), 9.57(\mathrm{~s}, 1 \mathrm{H}), 8.64(\mathrm{br} \mathrm{s}, 1 \mathrm{H}), 8.52(\mathrm{~s}, 1 \mathrm{H}), 8.23(\mathrm{~d}, J=8.1 \mathrm{~Hz}, 1 \mathrm{H}), 8.11(\mathrm{~d}, J=9.6 \mathrm{~Hz}, 1 \mathrm{H}), 7.88$ 
(d, J=8.7 Hz, 1H), $7.77(\mathrm{~s}, 1 \mathrm{H}), 7.72(\mathrm{br} \mathrm{d}, J=8.5 \mathrm{~Hz}, 1 \mathrm{H}), 7.49(\mathrm{t}, J=7.7 \mathrm{~Hz}, 1 \mathrm{H}), 7.36-7.27(\mathrm{~m}, 3 \mathrm{H}), 5.89(\mathrm{~s}$, 1H), $4.95(b r t, J=11.3 \mathrm{~Hz}, 1 \mathrm{H}), 4.19(\mathrm{br} \mathrm{d}, J=12.9 \mathrm{~Hz}, 2 \mathrm{H}), 3.86(\mathrm{~s}, 3 \mathrm{H}), 2.95-2.86(\mathrm{~m}, 2 \mathrm{H}), 2.27(\mathrm{~s}, 3 \mathrm{H})$, 2.20 - $2.07(\mathrm{~m}, 2 \mathrm{H}), 1.98(\mathrm{br} \mathrm{d}, J=11.3 \mathrm{~Hz}, 2 \mathrm{H}), 1.28(\mathrm{~s}, 9 \mathrm{H})$

Preparation of compound 11:
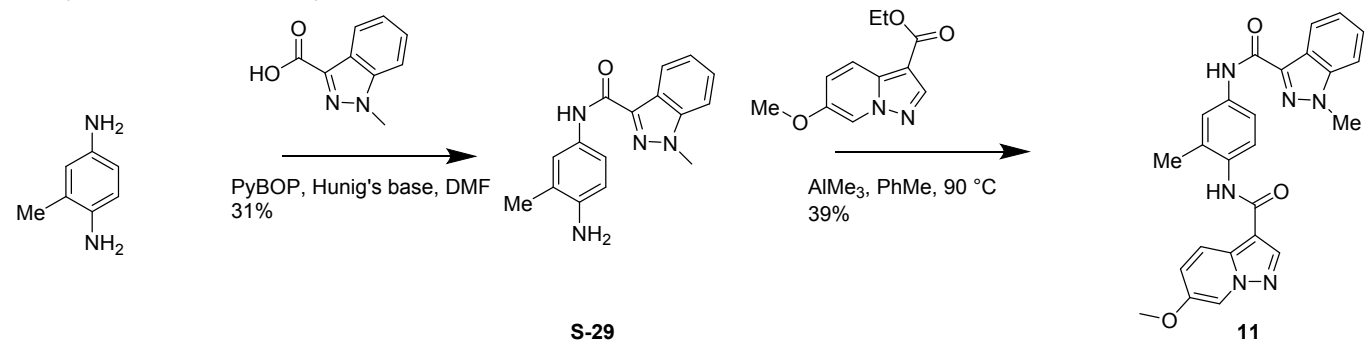

Preparation of (N-(4-amino-3-methylphenyl)-1-methyl-1H-indazole-3-carboxamide (S-29):

1-methyl-1H-indazole-3-carboxylic acid $(0.100 \mathrm{~g}, 0.568 \mathrm{mmol})$ and 2-methylbenzene-1,4-diamine, sulfuric acid salt $(0.250 \mathrm{~g}, 1.135 \mathrm{mmol})$ were suspended in DMF (1.892 ml). Hunig'sBase $(0.297 \mathrm{ml}, 1.703$ $\mathrm{mmol}$ ) and PyBOP (0.414 g, $0.795 \mathrm{mmol}$ ) were added and stirred for three days. The reaction was diluted with water and extracted twice with EtOAc. The organic layers were washed with $10 \% \mathrm{LiCl}$ solution, dried with sodium sulfate, and concentrated. The residue was purified via ISCO ( $24 \mathrm{~g}$ column; DCM/EtOAc; 0 to $25 \%$ gradient) to give $\mathrm{N}$-(4-amino-3-methylphenyl)-1-methyl-1H-indazole-3-

carboxamide (S-29) $(0.050 \mathrm{~g}, 0.178 \mathrm{mmol}, 31.4 \%$ yield). LC/MS RT: $0.63 \mathrm{~min}$ (Method A). M/Z= 281.1.

Preparation of ( N-(4-(6-methoxypyrazolo[1,5-a]pyridine-3-carboxamido)-3-methylphenyl)-1-methyl-1Hindazole-3-carboxamide (11):

To a suspension of ethyl 6-methoxypyrazolo[1,5-a]pyridine-3-carboxylate $(0.029 \mathrm{~g}, 0.134 \mathrm{mmol})$ andN(4-amino-3-methylphenyl)-1-methyl-1H-indazole-3-carboxamide (S-29) $(0.025 \mathrm{~g}, 0.089 \mathrm{mmol})$ in Toluene $(0.892 \mathrm{ml})$ was added trimethylaluminum ( $2 \mathrm{M}$ in toluene) $(0.067 \mathrm{ml}, 0.134 \mathrm{mmol})$. After ca. 5 minutes, the suspended solid had dissolved and the reaction was heated to $90{ }^{\circ} \mathrm{C}$ overnight. The reaction was cooled, then quenched with $\mathrm{MeOH}$. $1 \mathrm{M} \mathrm{HCl}$ was added, then the reaction was extracted once with EtOAc and once with DCM. The organic layers were concentrated. The material was dissolved in DMF, filtered through a syringe filter, and purified via preparative LC/MS with the following conditions:

Column: XBridge C18, $19 \times 200$ mm, 5- $\mu \mathrm{m}$ particles; Mobile Phase A: 5:95 acetonitrile: water with 10mM ammonium acetate; Mobile Phase B: 95:5 acetonitrile: water with 10-mM ammonium acetate; Gradient: $10-80 \%$ B over 17 minutes, then a 5-minute hold at $100 \%$ B; Flow: $20 \mathrm{~mL} / \mathrm{min}$. Fractions containing the desired product were combined and dried via centrifugal evaporation to giv( N-(4-(6methoxypyrazolo[1,5-a]pyridine-3-carboxamido)-3-methylphenyl)-1-methyl-1H-indazole-3-carboxamide (11) $(16.3 \mathrm{mg}, 37 \%)$. LCMS RT: $1.67 \mathrm{~min}$ (Method B). Purity $97 \% . \mathrm{M} / \mathrm{Z}=455.3$ and $909.1(2 \mathrm{M}+\mathrm{H})$ ${ }^{1} \mathrm{H}$ NMR $\left(500 \mathrm{MHz}, \mathrm{DMSO}-\mathrm{d}_{6}\right) \delta 10.28(\mathrm{~s}, 1 \mathrm{H}), 9.56(\mathrm{~s}, 1 \mathrm{H}), 8.64(\mathrm{br} \mathrm{s}, 1 \mathrm{H}), 8.53(\mathrm{~d}, J=1.6 \mathrm{~Hz}, 1 \mathrm{H}), 8.24(\mathrm{~d}$, $J=8.2 \mathrm{~Hz}, 1 \mathrm{H}), 8.11(\mathrm{~d}, J=9.7 \mathrm{~Hz}, 1 \mathrm{H}), 7.83(\mathrm{~s}, 1 \mathrm{H}), 7.79(\mathrm{~d}, J=8.5 \mathrm{~Hz}, 1 \mathrm{H}), 7.71$ (dd, J=8.5, $1.9 \mathrm{~Hz}, 1 \mathrm{H}), 7.51$ (t, J=7.7 Hz, 1H), $7.40-7.25(\mathrm{~m}, 3 \mathrm{H}), 4.21(\mathrm{~s}, 3 \mathrm{H}), 3.86(\mathrm{~s}, 3 \mathrm{H}), 2.26(\mathrm{~s}, 3 \mathrm{H})$

Preparation of compound 12: 

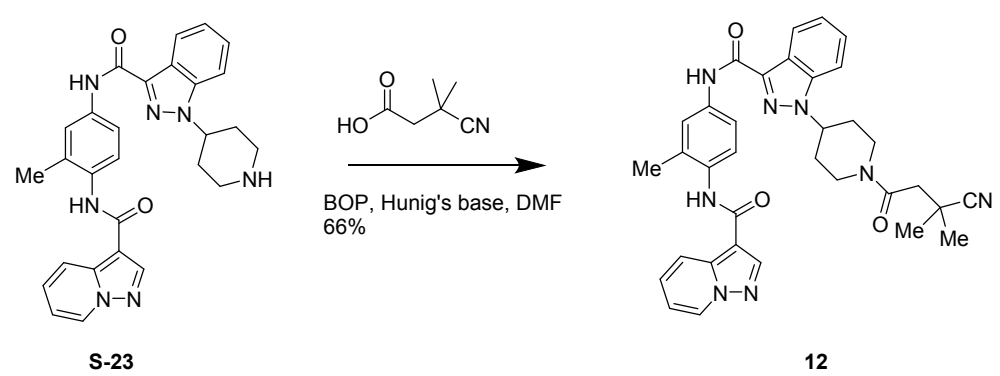

12

Preparation of 1-(1-(3-cyano-3-methylbutanoyl)piperidin-4-yl)-N-(3-methyl-4-(pyrazolo[1,5-a]pyridine-3carboxamido)phenyl)-1H-indazole-3-carboxamide (12)

To a solution of 3-cyano-3-methylbutanoic acid $(5.05 \mathrm{mg}, 0.040 \mathrm{mmol})$ and $\mathrm{N}$-(3-methyl-4-(pyrazolo[1,5a]pyridine-3-carboxamido)phenyl)-1-(piperidin-4-yl)-1H-indazole-3-carboxamide, $2 \mathrm{HCl}$ (S-23) $(0.015 \mathrm{~g}$, $0.026 \mathrm{mmol})$ in DMF $(0.3 \mathrm{~mL})$ was added Hunig'sBase $(0.018 \mathrm{~mL}, 0.106 \mathrm{mmol})$ and BOP $(0.018 \mathrm{~g}, 0.040$ mmol). After ca. 30 minutes, the reaction was quenched with $\mathrm{MeOH}$, diluted with DMF, and the crude material was purified via preparative LC/MS with the following conditions: Column: XBridge C18, $19 \mathrm{x}$ $200 \mathrm{~mm}, 5-\mu \mathrm{m}$ particles; Mobile Phase A: 5:95 acetonitrile: water with 10-mM ammonium acetate; Mobile Phase B: 95:5 acetonitrile: water with 10-mM ammonium acetate; Gradient: $20-80 \%$ B over 18 minutes, then a 5-minute hold at $100 \%$ B; Flow: $20 \mathrm{~mL} / \mathrm{min}$. Fractions containing the desired product were combined and dried via centrifugal evaporation to give 1-(1-(3-cyano-3-methylbutanoyl)piperidin4-yl)-N-(3-methyl-4-(pyrazolo[1,5-a]pyridine-3-carboxamido)phenyl)-1H-indazole-3-carboxamide (12) (10.6 mg, 66\%). LCMS RT: 1.71 min (Method B). Purity 100\%. M/Z=603.0. ${ }^{1} \mathrm{H}$ NMR (500 MHz, DMSO$\left.d_{6}\right) \delta$ ppm $10.06(1 \mathrm{H}, \mathrm{s}), 9.60(1 \mathrm{H}, \mathrm{s}), 8.83(1 \mathrm{H}, \mathrm{d}, \mathrm{J}=6.98 \mathrm{~Hz}), 8.75(1 \mathrm{H}, \mathrm{br} \mathrm{s}), 8.20-8.30(2 \mathrm{H}, \mathrm{m}), 7.91(1$ $\mathrm{H}, \mathrm{d}, \mathrm{J}=8.67 \mathrm{~Hz}), 7.79(1 \mathrm{H}, \mathrm{s}), 7.73(1 \mathrm{H}, \mathrm{br} \mathrm{d}, J=8.58 \mathrm{~Hz}), 7.51(2 \mathrm{H}, \mathrm{brt}, J=9.51 \mathrm{~Hz}), 7.27-7.39(2 \mathrm{H}, \mathrm{m})$, $7.10(1 \mathrm{H}, \mathrm{t}, J=6.77 \mathrm{~Hz}), 5.10(1 \mathrm{H}, \mathrm{brt}, J=10.98 \mathrm{~Hz}), 4.66(1 \mathrm{H}, \mathrm{br} \mathrm{d}, J=12.79 \mathrm{~Hz}), 4.07(1 \mathrm{H}, \mathrm{br} d, J=13.21$ $\mathrm{Hz}), 3.30(1 \mathrm{H}, \mathrm{brd}, J=12.03 \mathrm{~Hz}), 2.89(1 \mathrm{H}, \mathrm{s}), 2.74-2.85(2 \mathrm{H}, \mathrm{m}), 2.28(3 \mathrm{H}, \mathrm{s}), 2.01-2.22(4 \mathrm{H}, \mathrm{m}), 1.41$ $(6 \mathrm{H}, \mathrm{br} \mathrm{d}, J=8.16 \mathrm{~Hz})$.

Preparation of compound 13:

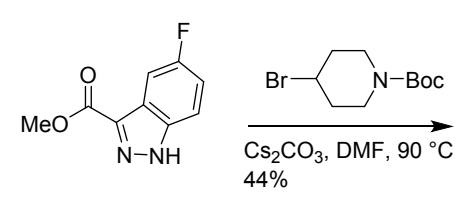

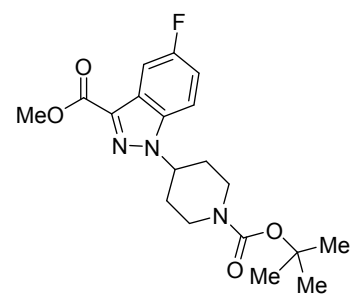

S-30
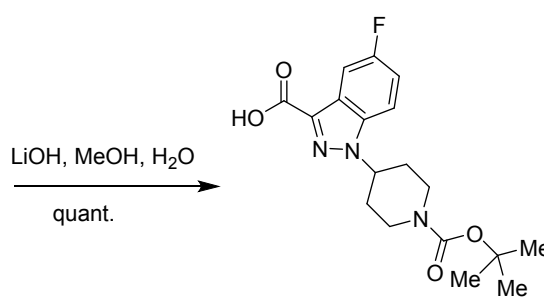

S-31

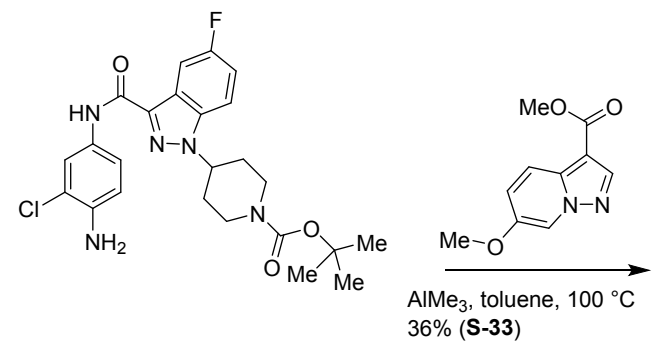

S-32

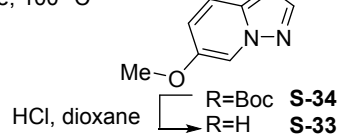

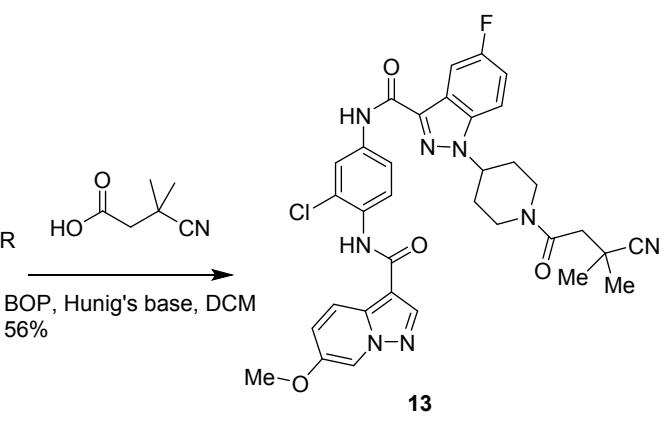
$56 \%$

Preparation of methyl 1-(1-(tert-butoxycarbonyl)piperidin-4-yl)-5-fluoro-1H-indazole-3-carboxylate (S30): 
A solution of methyl 5-fluoro-1H-indazole-3-carboxylate $(1 \mathrm{~g}, 5.15 \mathrm{mmol})$ and tert-butyl 4-

bromopiperidine-1-carboxylate $(2.041 \mathrm{~g}, 7.73 \mathrm{mmol})$ in DMF $(17.17 \mathrm{ml})$ was stirred at $90^{\circ} \mathrm{C}$ for 16 hours. Then the mixture was diluted with $20 \mathrm{~mL}$ of aqueous $\mathrm{NaHCO}_{3}$ and $40 \mathrm{~mL}$ of DCM. The organic layer was washed with brine and dried over $\mathrm{Na}_{2} \mathrm{SO}_{4}$, then concentrated. The residue was purified by ISCO (24 g column, $0 \rightarrow 60 \%$ EtOAc in Hexane) to afford the undesired regioisomer methyl 2-(1-(tertbutoxycarbonyl)piperidin-4-yl)-5-fluoro-2H-indazole-3-carboxylate and the desired regioisomer methyl 1-(1-(tert-butoxycarbonyl)piperidin-4-yl)-5-fluoro-1H-indazole-3-carboxylate (S-30) (855 mg, 2.265 $\mathrm{mmol}, 44.0 \%$ yield). The desired isomer eluted after the undesired one. ${ }^{1} \mathrm{H} \mathrm{NMR}(400 \mathrm{MHz}$, CHLOROFORM-d) $\delta 7.83$ (dd, J=8.6, 2.2 Hz, 1H), 7.46 (dd, J=9.2, 3.8 Hz, 1H), 7.19 (td, J=8.9, 2.4 Hz, $1 \mathrm{H}$ ), $4.63(\mathrm{tt}, J=11.6,4.1 \mathrm{~Hz}, 1 \mathrm{H}), 4.33(\mathrm{br} \mathrm{s}, 2 \mathrm{H}), 4.00$ (s, 3H), 2.93 (br s, 2H), 2.29 (br d, J=10.4 Hz, $2 \mathrm{H}), 2.07$ $1.97(\mathrm{~m}, 2 \mathrm{H}), 1.47(\mathrm{~s}, 9 \mathrm{H})$.

Preparation 1-(1-(tert-butoxycarbonyl)piperidin-4-yl)-5-fluoro-1H-indazole-3-carboxylic acid (S-31): To a solution of methyl 1-(1-(tert-butoxycarbonyl)piperidin-4-yl)-5-fluoro-1H-indazole-3-carboxylate $(0.130 \mathrm{~g}, 0.344 \mathrm{mmol})(\mathrm{S}-30)$ in methanol $(2.76 \mathrm{ml})$ and $\mathrm{H}_{2} \mathrm{O}(0.689 \mathrm{ml})$ was added lithium hydroxide, $\mathrm{H} 2 \mathrm{O}(0.043 \mathrm{~g}, 1.033 \mathrm{mmol})$. After 4 hours, the reaction was partially concentrated, acidified to $\mathrm{pH} 1$ with $1 \mathrm{M} \mathrm{HCl}$, and extracted twice with EtOAc. The organic layers were concentrated to give 1-(1-(tertbutoxycarbonyl)piperidin-4-yl)-5-fluoro-1H-indazole-3-carboxylic acid (S-31) (0.125 g, 0.344 mmol, 100 $\%$ yield). LC/MS RT: $0.89 \min$ (Method A). M/Z= 308.1.

Preparation of tert-butyl 4-(3-((4-amino-3-chlorophenyl)carbamoyl)-5-fluoro-1H-indazol-1-yl)piperidine1-carboxylate (S-32):

To a solution of 2-chlorobenzene-1,4-diamine, sulfuric acid salt $(0.993 \mathrm{~g}, 4.13 \mathrm{mmol})$ and 1-(1-(tertbutoxycarbonyl)piperidin-4-yl)-5-fluoro-1H-indazole-3-carboxylic acid (S-31) (1.0 g, $2.75 \mathrm{mmol})$ in DMF $(13.76 \mathrm{ml})$ was added Hunig's Base $(2.403 \mathrm{ml}, 13.76 \mathrm{mmol})$ and PyBOP $(1.862 \mathrm{~g}, 3.58 \mathrm{mmol})$. After 6 hours, $250 \mathrm{mg}$ PyBOP and $0.5 \mathrm{~mL}$ Hunig's base were added. The reaction was stirred overnight, then diluted with water and extracted twice with EtOAc. The organic layers were washed with $10 \% \mathrm{LiCl}$ solution, dried with sodium sulfate, and concentrated. The residue was purified via ISCO ( $120 \mathrm{~g}$ column; $\mathrm{CH} 2 \mathrm{Cl} 2 /$ EtOAc; 0 to $30 \%$ gradient) to give tert-butyl 4-(3-((4-amino-3-chlorophenyl)carbamoyl)-5-fluoro$1 \mathrm{H}$-indazol-1-yl)piperidine-1-carboxylate (S-32) (1.11 g, $2.275 \mathrm{mmol}, 83 \%$ yield). LC/MS RT: $1.06 \mathrm{~min}$ (Method A). M/Z= 488.1.

Preparation of ( N-(3-chloro-4-(6-methoxypyrazolo[1,5-a]pyridine-3-carboxamido)phenyl)-5-fluoro-1(piperidin-4-yl)-1H-indazole-3-carboxamide (S-33):

To a suspension of methyl 6-methoxypyrazolo[1,5-a]pyridine-3-carboxylate $(0.169 \mathrm{~g}, 0.820 \mathrm{mmol})$ and tert-butyl 4-(3-((4-amino-3-chlorophenyl)carbamoyl)-5-fluoro-1H-indazol-1-yl)piperidine-1-carboxylate (S-32) $(0.250 \mathrm{~g}, 0.512 \mathrm{mmol})$ in toluene $(5.12 \mathrm{ml})$ was added trimethylaluminum (2M in toluene) $(0.640$ $\mathrm{ml}, 1.281 \mathrm{mmol})$. Suspended material dissolved slowly and the reaction was heated to $100{ }^{\circ} \mathrm{C}$ overnight. LCMS showed that the Boc group was partially cleaved during the reaction. The reaction was cooled, then quenched with $\mathrm{MeOH}$ and $1 \mathrm{M} \mathrm{NaOH}$. The reaction was absorbed onto sillica gel. The residue was purified via ISCO ( $40 \mathrm{~g}$ column; DCM; 0 to $10 \%$ gradient, then flush to $35 \% \mathrm{MeOH})$. N-(3-chloro-4-(6methoxypyrazolo[1,5-a]pyridine-3-carboxamido)phenyl)-5-fluoro-1-(piperidin-4-yl)-1H-indazole-3carboxamide (S-33) (0.104 g, $0.185 \mathrm{mmol}, 36.1 \%$ yield) was obtained. LC/MS RT: $0.78 \mathrm{~min}$ (Method A). $M / Z=562.1$.

$260 \mathrm{mg}$ of a ca. 1:1-1.3 mixture of S-34 and ester starting material was also obtained. S-34 could be converted to S-33 as described for the preparation of S-28. 
Preparation of N-(3-chloro-4-(6-methoxypyrazolo[1,5-a]pyridine-3-carboxamido)phenyl)-1-(1-(3-cyano3-methylbutanoyl)piperidin-4-yl)-5-fluoro-1H-indazole-3-carboxamide (13):

To a suspension of N-(3-chloro-4-(6-methoxypyrazolo[1,5-a]pyridine-3-carboxamido)phenyl)-5-fluoro-1(piperidin-4-yl)-1H-indazole-3-carboxamide, $2 \mathrm{HCl}(\mathbf{S}-33)(0.250 \mathrm{~g}, 0.393 \mathrm{mmol})$ and 3-cyano-3-

methylbutanoic acid $(0.050 \mathrm{~g}, 0.393 \mathrm{mmol})$ in DCM $(3.93 \mathrm{ml})$ was added Hunig's Base $(0.480 \mathrm{ml}, 2.75$ $\mathrm{mmol}$ ) and BOP (0.174 g, $0.393 \mathrm{mmol})$. After 1.75 hours, $35 \mathrm{mg}$ 3-cyano-3-methylbutanoic acid, $90 \mathrm{mg}$ $\mathrm{BOP}$, and $300 \mu \mathrm{L}$ Hunig's base were added. After 1 hour, the reaction was quenched with $\mathrm{MeOH}$ and concentrated. The residue was absorbed onto silica gel. The residue was purified via ISCO ( $24 \mathrm{~g}$ column; $\mathrm{DCM} / \mathrm{MeOH} ; 0$ to $7 \%$ gradient, then flush to $20 \%)$. The solid was washed with water/MeOH and dried to give N-(3-chloro-4-(6-methoxypyrazolo[1,5-a]pyridine-3-carboxamido)phenyl)-1-(1-(3-cyano-3-

methylbutanoyl)piperidin-4-yl)-5-fluoro-1H-indazole-3-carboxamide (13) $(0.152 \mathrm{~g}, 0.219 \mathrm{mmol}, 55.7 \%$ yield). HPLC RT: $10.68 \mathrm{~min}$ (Method B). Purity 97\%. ${ }^{1} \mathrm{H}$ NMR (400 MHz, DMSO-d 6 ) $\delta 10.32$ (s, 1H), 9.69 $(\mathrm{s}, 1 \mathrm{H}), 8.68(\mathrm{~s}, 1 \mathrm{H}), 8.55(\mathrm{~d}, J=1.8 \mathrm{~Hz}, 1 \mathrm{H}), 8.17(\mathrm{~d}, J=2.3 \mathrm{~Hz}, 1 \mathrm{H}), 8.11(\mathrm{~d}, J=9.6 \mathrm{~Hz}, 1 \mathrm{H}), 8.02$ (dd, J=9.3, $4.3 \mathrm{~Hz}, 1 \mathrm{H}$ ), $7.87(\mathrm{td}, J=8.5,2.4 \mathrm{~Hz}, 2 \mathrm{H}), 7.59$ (d, J=8.7 Hz, 1H), 7.46 (td, J=9.1, $2.5 \mathrm{~Hz}, 1 \mathrm{H}$ ), 7.33 (dd, J=9.6, $2.2 \mathrm{~Hz}, 1 \mathrm{H}), 5.19-5.07(\mathrm{~m}, 1 \mathrm{H}), 4.70-4.62(\mathrm{~m}, 1 \mathrm{H}), 4.14-4.03(\mathrm{~m}, 1 \mathrm{H}), 3.87(\mathrm{~s}, 3 \mathrm{H}), 3.30-3.25(\mathrm{~m}, 1 \mathrm{H})$, $2.93-2.73(\mathrm{~m}, 3 \mathrm{H}), 2.25-2.05(\mathrm{~m}, 4 \mathrm{H}), 1.42(\mathrm{~d}, \mathrm{~J}=5.9 \mathrm{~Hz}, 6 \mathrm{H}) .{ }^{13} \mathrm{C}$ NMR $\left(126 \mathrm{MHz}\right.$, DMSO- $\left.\mathrm{d}_{6}\right) \delta 166.9$, 161.2, 160.4, 158.5 (br d, J=238.9 Hz, 1C), 149.8, 141.0, 137.2, 137.1, 136.5 (br d, J=5.4 Hz, 1C), 136.3, 130.3, 129.0, 128.5, 125.2, 122.5 (br d, J=11.8 Hz, 1C), 121.7, 120.8, 119.2, 118.4, 116.4 (br d, J=27.2 Hz, 1C), 112.6 (br d, $J=10.0 \mathrm{~Hz}, 1 \mathrm{C}$ ), 112.3, 105.9, 105.4 (br d, J=24.5 Hz, 1C), 56.4, 55.5, 43.8 (br s, 1C), 41.4, 39.45 - 39.42 (m, 1C), 31.9 (br s, 1C), 30.9 (br s, 1C), 29.7, 26.7, 26.4. ${ }^{19} \mathrm{~F}$ NMR (376 MHz, DMSO-d 6 ) $\delta$ 119.63 (s, 1F) HRMS: calculated for $\mathrm{C}_{34} \mathrm{H}_{33} \mathrm{O}_{4} \mathrm{~N}_{8} \mathrm{ClF} 671.2292$ found 671.2283.

Preparation of compound 14:
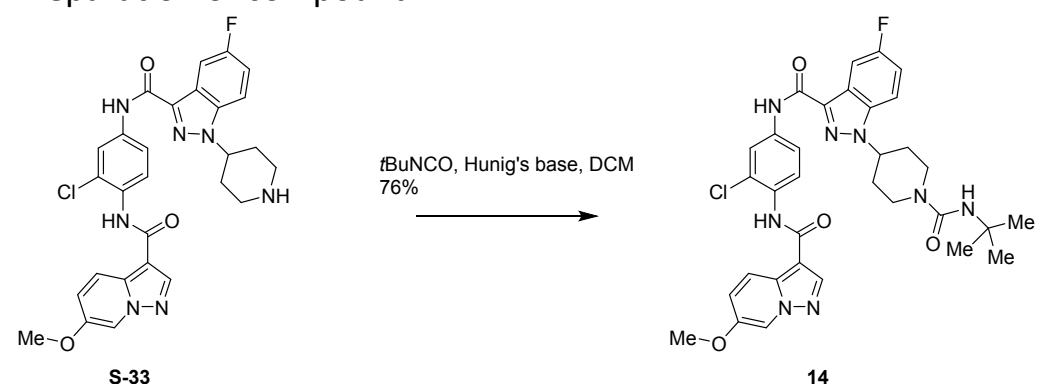

Preparation of 1-(1-(tert-butylcarbamoyl)piperidin-4-yl)-N-(3-chloro-4-(6-methoxypyrazolo[1,5a]pyridine-3-carboxamido)phenyl)-5-fluoro-1H-indazole-3-carboxamide (14):

To a suspension of $\mathrm{N}$-(3-chloro-4-(6-methoxypyrazolo[1,5-a]pyridine-3-carboxamido)phenyl)-5-fluoro-1(piperidin-4-yl)-1H-indazole-3-carboxamide (S-33) $(20 \mathrm{mg}, 0.036 \mathrm{mmol})$ in DCM $(0.300 \mathrm{~mL})$ was added Hunig'sBase $(0.037 \mathrm{~mL}, 0.214 \mathrm{mmol})$ and 2-isocyanato-2-methylpropane $(4.88 \mu \mathrm{l}, 0.043 \mathrm{mmol})$. The reaction was stirred at $\mathrm{rt}$ for 3 hours. The solvent was evaporated and the residue was purified by ISCO (12 g column, $0 \rightarrow 10 \% \mathrm{MeOH}$ in DCM) to afford 1-(1-(tert-butylcarbamoyl)piperidin-4-yl)-N-(3-chloro-4(6-methoxypyrazolo[1,5-a]pyridine-3-carboxamido)phenyl)-5-fluoro-1H-indazole-3-carboxamide (14) (18 $\mathrm{mg}, 0.027 \mathrm{mmol}, 76 \%$ yield) as an offwhite solid. HPLC RT: $22.73 \mathrm{~min}$ (Method A). Purity $97 \% . \mathrm{M} / \mathrm{Z}=$ 661.5. ${ }^{1} \mathrm{H}$ NMR (400MHz, METHANOL- $\left.\mathrm{d}_{4}\right) \delta 8.55(\mathrm{~s}, 1 \mathrm{H}), 8.35(\mathrm{~d}, J=1.6 \mathrm{~Hz}, 1 \mathrm{H}), 8.19-8.15(\mathrm{~m}, 2 \mathrm{H}), 7.94$ (dd, J=8.8, 2.3 Hz, 1H), 7.82 (dd, J=9.3, 3.9 Hz, 1H), 7.77 - $7.74(\mathrm{~m}, 2 \mathrm{H}), 7.38$ - $7.27(\mathrm{~m}, 2 \mathrm{H}), 4.97$ - $4.92(\mathrm{~m}$, 1H), $4.25(\mathrm{~d}, \mathrm{~J}=13.3 \mathrm{~Hz}, 2 \mathrm{H}), 3.93(\mathrm{~s}, 3 \mathrm{H}), 3.08(\mathrm{t}, J=12.0 \mathrm{~Hz}, 2 \mathrm{H}), 2.36-2.23(\mathrm{~m}, 2 \mathrm{H}), 2.11(\mathrm{~d}, \mathrm{~J}=10.3 \mathrm{~Hz}$, $2 \mathrm{H}), 1.40(\mathrm{~s}, 9 \mathrm{H})$. 
NMR Spectra of compound 4:

Compound $4{ }^{1} \mathrm{H}$ Spectrum $\left(\mathrm{CD}_{3} \mathrm{OD}\right)$ :

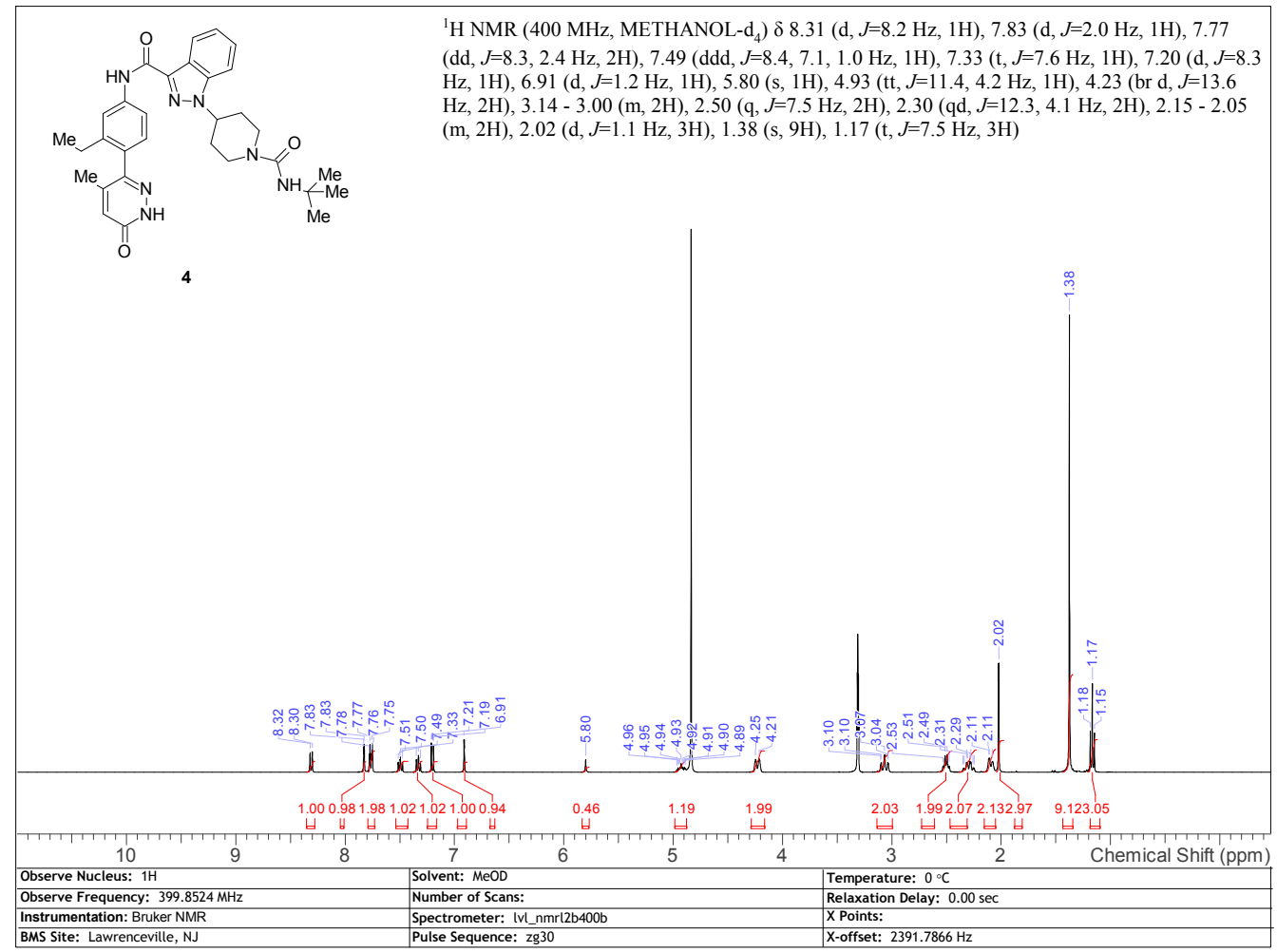

\section{Compound $4{ }^{13} \mathrm{C}$ Spectrum $\left(\mathrm{CD}_{3} \mathrm{OD}\right)$ :}

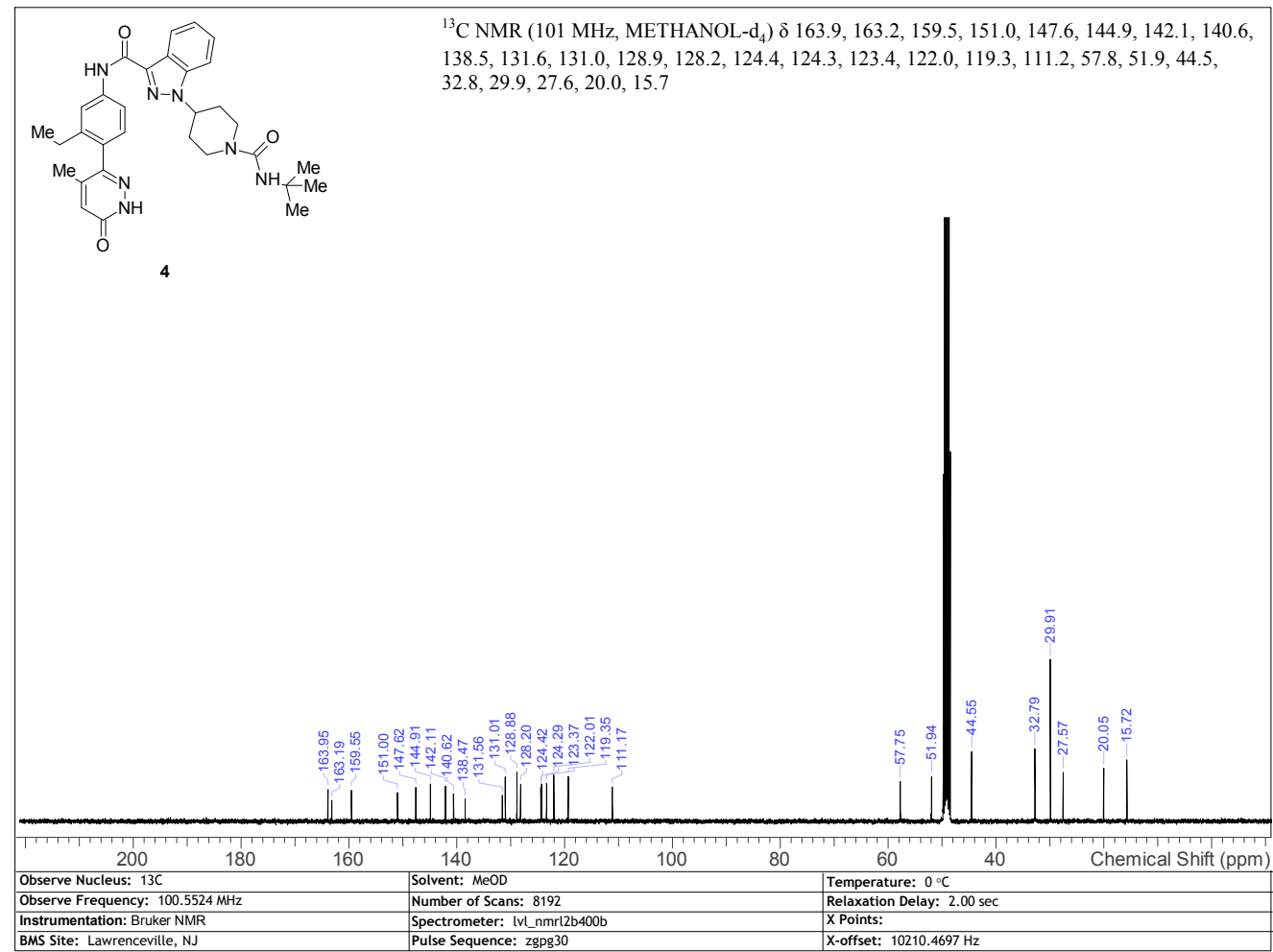




\section{${ }^{1} \mathrm{H}$ Spectrum of Compound 13 (DMSO- $d_{6}$ ):}

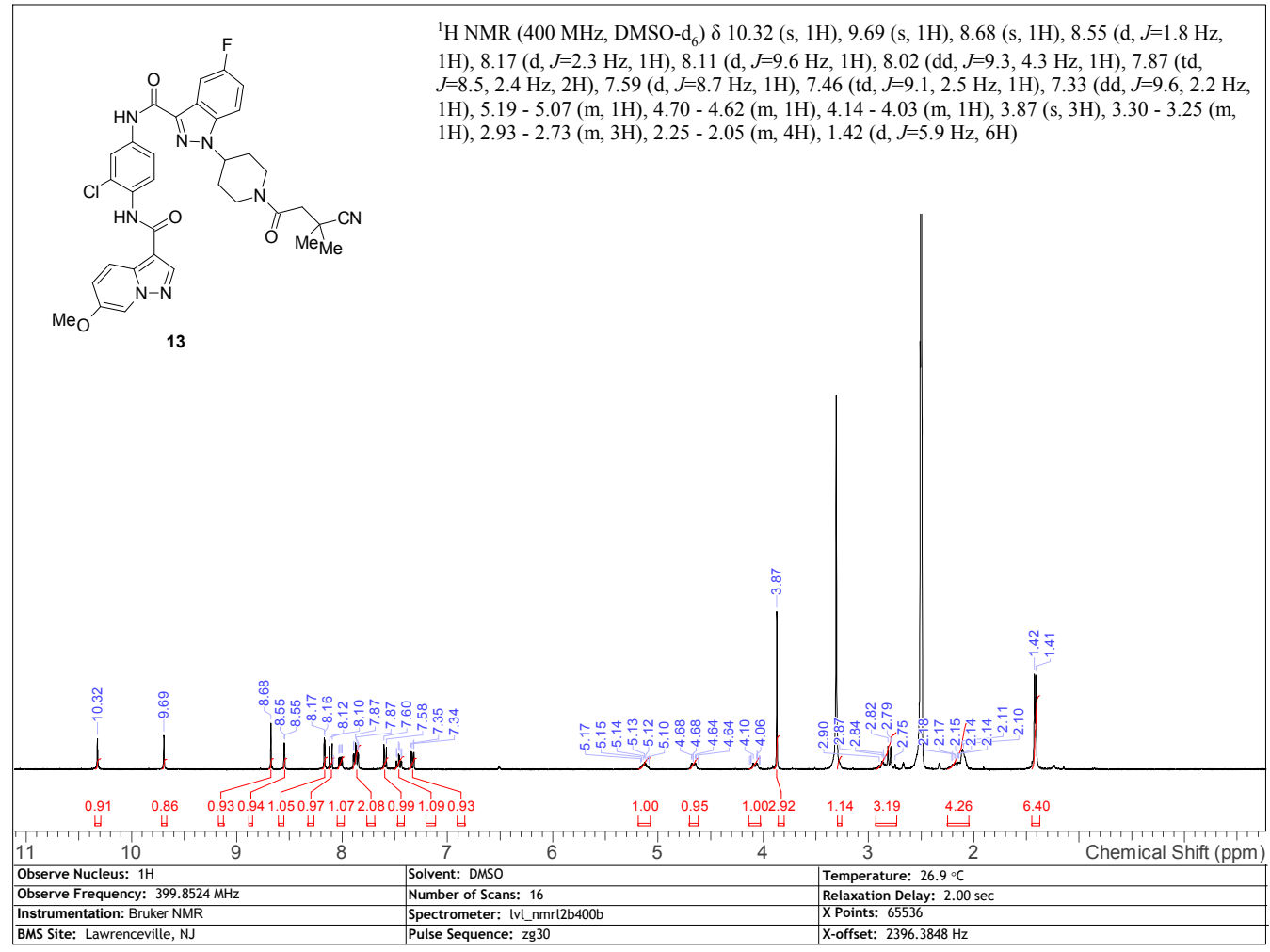

\section{${ }^{13} \mathrm{C}$ Spectrum of Compound 13 (DMSO- $d_{6}$ ):}

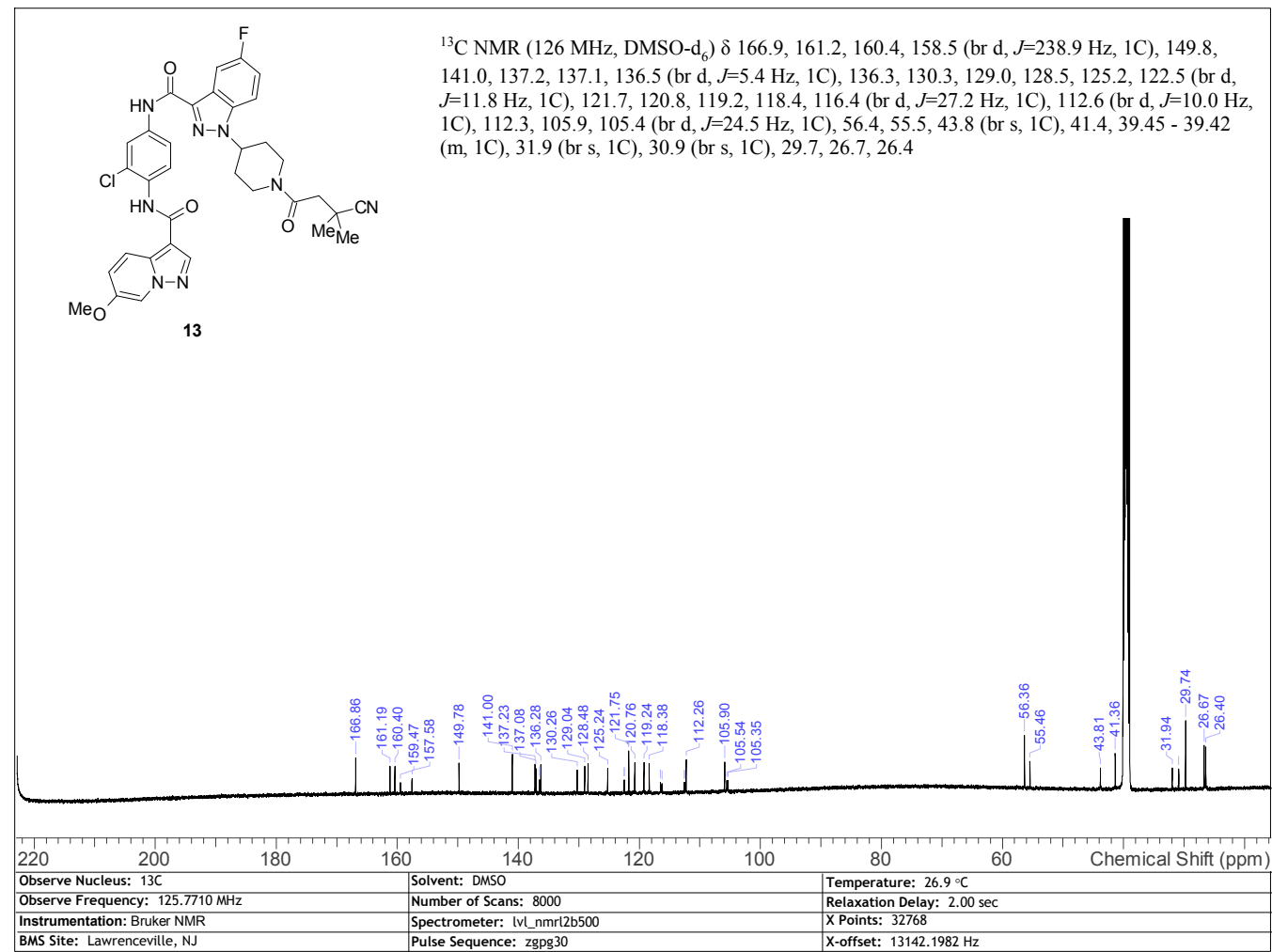


HMQC Spectrum of Compound 13 (DMSO- $\left.d_{6}\right)::$

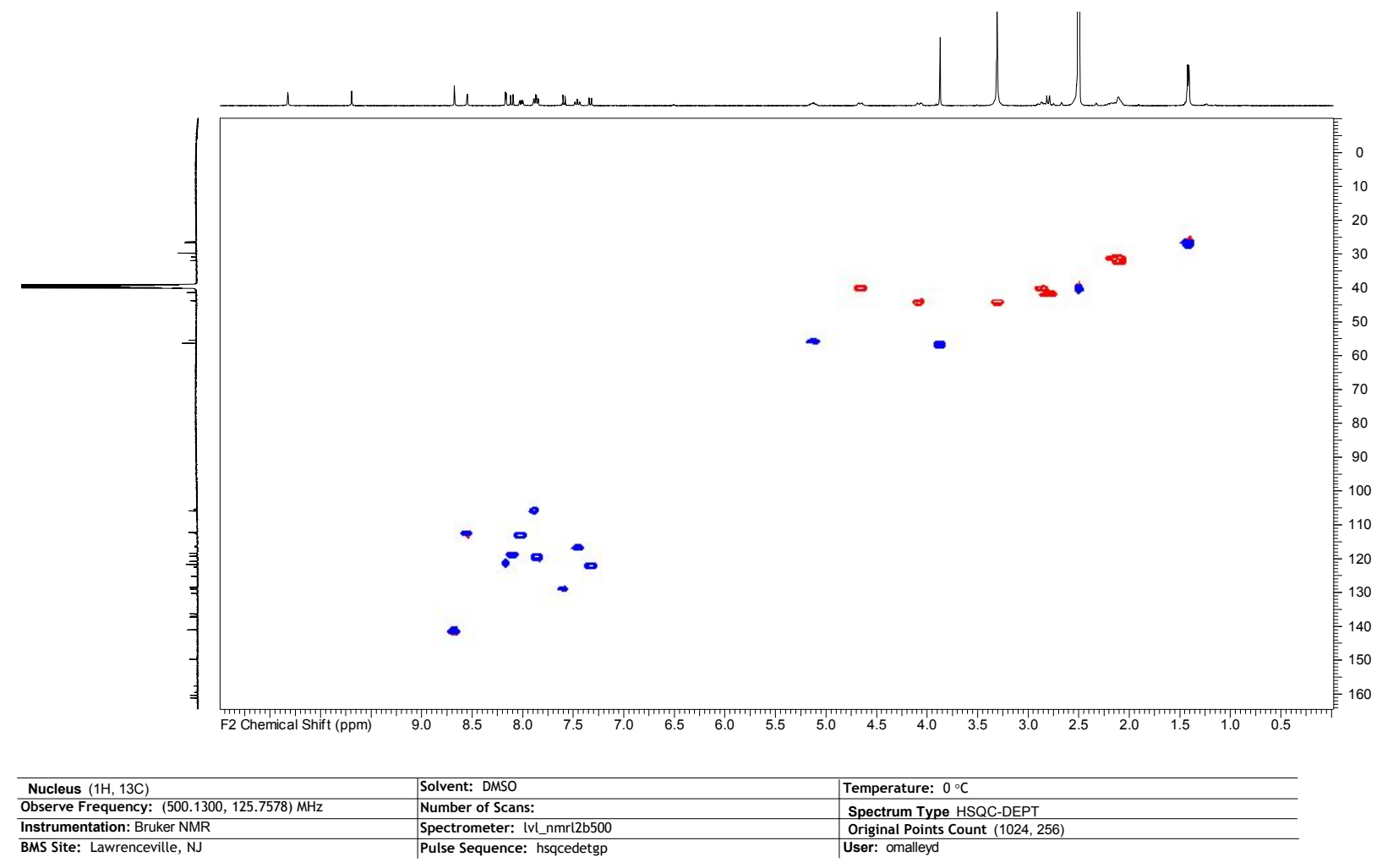

HMBC Spectrum of Compound 13 (DMSO- $d_{6}$ ):

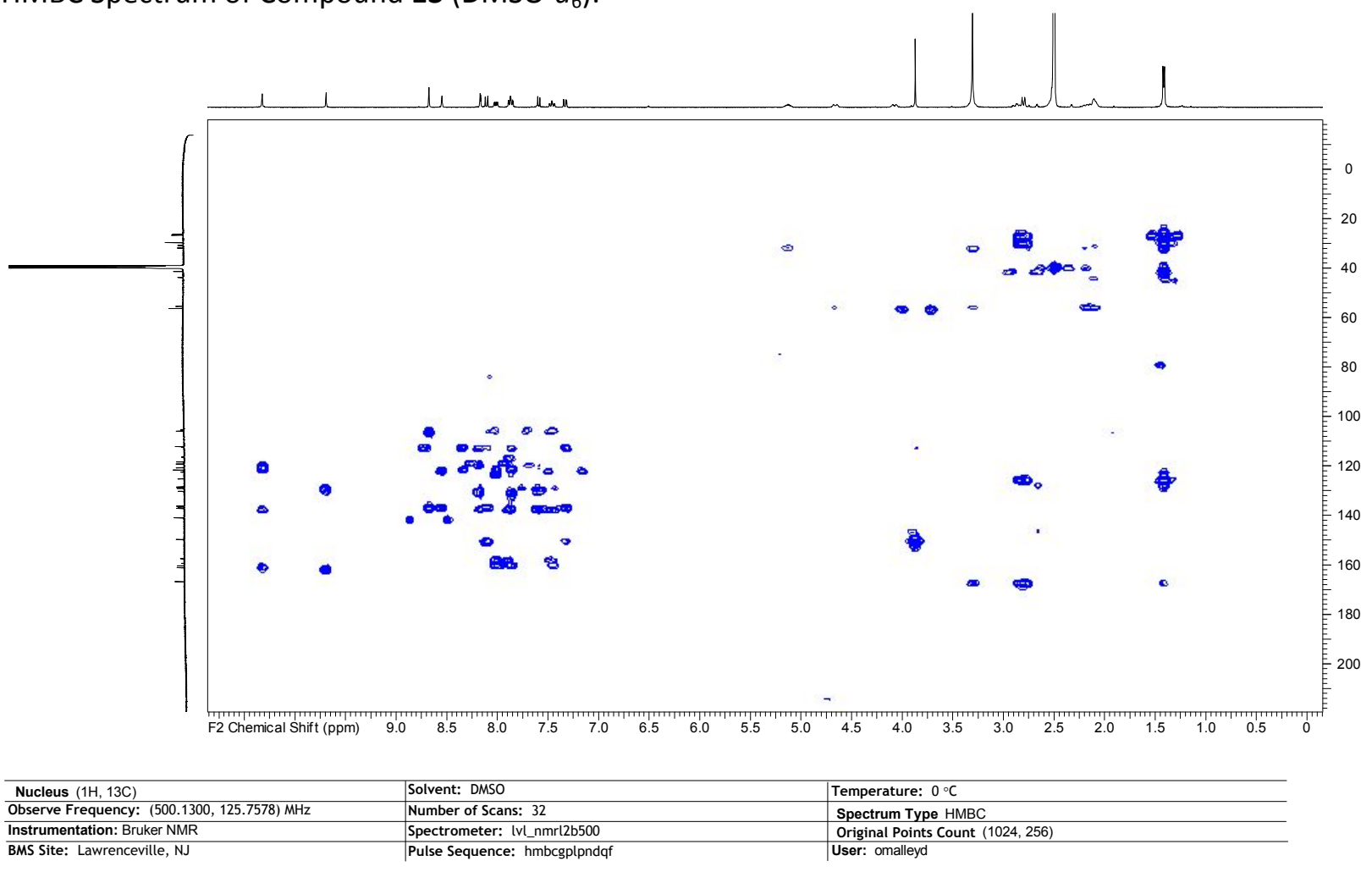


Kinome Selectivity Data for Compounds $\mathbf{4 , 6 , 1 3}$, and $\mathbf{1 4}$. Kinases with an $I C_{50}$ value within 100 fold of the Csk value are listed; only kinases with $\mathrm{IC}_{50}$ values $<1 \mu \mathrm{M}$ are listed for compound 4.

Kinome Selectivity for Compound $\mathbf{4}$

\begin{tabular}{|c|c|}
\hline Kinase & Kinase \\
\hline BMX & MAP4K3 \\
\hline FES & Sek1 \\
\hline
\end{tabular}

Kinome Selectivity for Compound 6

\begin{tabular}{|c|c|c|}
\hline Kinase & Kinase & Kinase \\
\hline BMX & FES & ROCK1 \\
\hline MAP4K3 & ROCK2 & \\
\hline
\end{tabular}

Kinome Selectivity for Compound 13

\begin{tabular}{|c|c|c|}
\hline Kinase & Kinase & Kinase \\
\hline BMX & EPHA4 & EPHB4 \\
\hline EPH2B & BTK & FGR \\
\hline HER4 & EPHA8 & LCK \\
\hline ARG & Abl & BRAF \\
\hline RAF1 & LYN & EPHA2 \\
\hline EPHA5 & EPHB1 & \\
\hline
\end{tabular}

Kinome Selectivity for Compound 14

\begin{tabular}{|c|c|c|}
\hline Kinase & Kinase & Kinase \\
\hline Abl & EPHB2 & RAF1 \\
\hline BMX & EPHB1 & BTK \\
\hline FGR & EPHA4 & EPHA2 \\
\hline EPHA5 & HER4 & YES \\
\hline EPHA8 & LCK & SRC \\
\hline ARG & EPHB4 & \\
\hline TYK2b & LYN & \\
\hline
\end{tabular}

